WellBeing International

WBI Studies Repository

1985

\title{
Three Blind Mice, See How They Run: A Critique of Behavioral Research With Animals
}

Michael A. Giannelli

The Fund for Animals

Follow this and additional works at: https://www.wellbeingintlstudiesrepository.org/acwp_arte

Part of the Animal Experimentation and Research Commons, Animals Commons, and the Other Psychiatry and Psychology Commons

\section{Recommended Citation}

Giannelli, M.A. (1985). Three blind mice, see how they run: A critique of behavioral research with animals. In M.W. Fox \& L.D. Mickley (Eds.), Advances in animal welfare science 1985/86 (pp. 109-164). Washington, DC: The Humane Society of the United States.

This material is brought to you for free and open access by WellBeing International. It has been accepted for inclusion by an authorized administrator of the WBI Studies Repository. For more information, please contact wbisr-info@wellbeingintl.org.

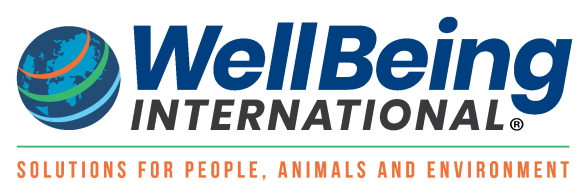




\section{THREE BLIND MICE, SEE HOW THEY RUN: A CRITIQUE OF BEHAVIORAL RESEARCH WITH ANIMALS}

\section{Michael A. Giannelli}

The Fund for Animals

12548 Ventura Blvd.

Suite 141

Studio City, $C A$

91604

\section{Introduction}

Animal research has been a traditionally accepted and respected part of modern psychology from its earliest days. The prevalent view of animals in contemporary psychology has origins far more basic than the scientific method. Its roots are deeply imbedded in Judaeo-Christian culture, a tradition which postulates a wide gulf between humankind and the animal world. The Darwinian revolution and the ethological outlook it fostered, while of immense biological significance, has for the most part been neglected by modern American comparative psychologists in favor of a positivistic-behaviorist orientation with a heavy reliance upon laboratory experimentation.

In recent years, opposition to animal research (some of it rational, some not) has experienced a profound resurgence. Psychologists have received a disproportionate share of the criticism considering the relatively small numbers of animals sacrificed in psychology laboratories. In this paper, I propose to review this development, critically examine the response of orthodox psychology to it, and offer suggestions for improvement.

Animal research in psychology has come under fire from a variety of sources and for a variety of reasons. Mellgren, et al. (1984) described the problem in relatively mild terms: 
Animal psychologists have been undergoing an identity crisis, with increasingly common criticisms of the traditional field revolving around the assumption that laboratory preparations alone will reveal laws of learning having generality. Such criticisms have taken many forms but may be reduced to the criticism that animal psychologists have ignored the biological predispositions of their subjects and by doing so may have distorted the true nature of the subjects' learning capacities, motivational processes, and so on (p. 142).

Rollin (1981) offered a more vociferous critique:

It is perhaps better to focus upon the field most consistently guilty of mindless activity that results in great suffering. This is the field of experimental, behavioral, comparative, and sometimes physiological psychology. Nowhere are researchers further removed from theory, nowhere are researchers less engaged in trying to develop a picture of some aspect of the world, nowhere are researchers less able to discuss intelligently the significance of their experiments, nowhere are researchers less concerned with the morality of what they do (p. 124)....Besides the potential pernicious consequences for human beings, the lack of theory, the empirical dabblings, and the trial-and-error approach that characterize behavioral and physiological psychology are extremely mischievous from the point of view of animal suffering. Suffering is essential to psychological research in a way that is unparalleled in all other research, except research on anesthetics and analgesics. A basic feature of behavioral psychological research is the use of negative reinforcement (i.e., pain, anxiety, stress, etc.) to condition animal behavior in various ways. It is for this reason that I am so strongly critical of psychological research.... It is extremely revealing and interesting that other scientists who work with animals, even strong defenders of the researcher's right to use animals, have great contempt for behavioral psychology and point out that by far the most cruel and useless experiments are done by psychologists, and that these experiments give all researchers a bad name (p. 126).

Regrettably, spokespersons for institutionalized psychology (e.g., King 1984; Miller 1985) have conveyed the impression that their only serious critics are animal rights advocates with little understanding of or appreciation for science. This defense is demonstrably false and misleading as this paper will show. Additionally, specific written assurances have been offered by the American Psychological Association (APA) purporting to describe legal and professional safeguards for the "humane" treatment of laboratory animals. While it is beyond the scope of the present work to comprehensively counter these claims, elsewhere I have discussed the major defects in the relevant laws and professional guidelines (Giannelli 1985). It will suffice to say at this point that the great majority of species used in psychological work (i.e., mice and rats) are not covered by Federal regulation, the Animal Welfare Act (1966, 1970, 1976). Further, such laws and guidelines as do exist expressly allow the infliction of pain without benefit of anesthesics, analgesics, or tranquilizers. 
In an atypical presidential address to the APA, William Bevan (1982) made the following appeal: "We must somehow reconcile our needs for a technology based on science with those for a humanely inspired culture.... We can no longer confidently believe that the effects of science and technology upon the fate of society are always unidirectional and beneficent."

I suspect that the majority of my colleagues in psychology would readily see the reasonableness of Dr. Bevan's point, but would be miffed at the suggestion that we psychologists share the blame. The tradition of untrammeled inquiry in the behavioral sciences has been at best a mixed blessing. Animal experimentation in psychology should neither be universally condemned nor universally applauded. However, the orthodox scientific and ethical justifications for much of this work are rightfully being challenged, especially the behaviorist methodology which is the predominant animal research paradigm in psychology.

I became a clinician because I am keenly interested in people. During my undergraduate training at the University of California, Los Angeles (UCLA), I learned about the work of famous animal researchers such as Pavlov, Thorndike, Harlow, Skinner and others. The ethics of such work was not discussed by my professors. This omission struck me as odd, particularly in light of some research we learned about. For example, in Abnormal Psychology and Modern Life (Coleman and Broen 1972), the most popular introductory text of its day, one finds a table (p. 149) titled, "Effects of Early Deprivation and Trauma on Adult Behavior of Animals." It mentioned the following early experiences: "raised in darkness or with restricted tactual stimulation," "immobilization of movement in early infancy," "partial starvation in early infancy," "total social isolation for six months or more after birth," "subjected to aversive stimulation such as electroshock or loud noise," "raised in an overcrowded environment," and "trained to fight over food." The book had graphic descriptions of "experimentally induced neuroses":

Monkeys, in addition to anxiety and phobic reactions, like those shown by the cats, displayed even more profound disturbances. Somatic and motor dysfunctions included diarrhea and gastrointestinal disorders resulting in rickets and severe neuromuscular weakness. In contrast to their previous behavior, some monkeys after experimental treatment spent long periods in stereotyped repetitive activity such as "pacing" back and forth in the experimental cage. Sometimes this behavior alternated with states of tense, apprehensive immobility. Some animals would stare fixedly for hours if left undisturbed. Often thse monkeys would sleep or lie immobile in their home cages until midafternoon. Homosexual and autoerotic activity increased markedly, even in the presence of receptive females. One monkey attempted coitus only once in six months. "Neurotic" animals also lost their former positions of dominance in relation to other animals and were frequently attacked by other members of the colony (p. 258). 
All of this might have been rationalized by reference to "essential clinical insights" which benefit people and which could not have otherwise been obtained. But, the qualifier was found elsewhere, "It is risky, of course, to assume that conclusions drawn from animal studies will be found to apply on the human level." No one ever said anything. I said nothing. What could one say?

People are often surprised to hear that in the course of my graduate level clinical studies at UCLA or in my clinical internships, animal research was not formally discussed at all. This, I came to realize, was not an oversight in my training (a program still considered one of the best in the country) but rather it reflected a conspicuous lack of practical importance animal experiments have had in the making of a psychotherapist. Of course, animal research in psychology has generated an enormous amount of sheer information. We have learned a great deal about how primates, dogs, cats, pigs, pigeons, and rodents behave in highly artificial (and often stressful) situations. But the practical importance and relevance to people of much of this data is highly questionable. Over the years, I regrettably came to the conclusion that many psychological experiments with animals are a particularly clear illustration of how animal research can and often does become an end-in-itself, a self-perpetuating (and often self-congratulating) industry.

\section{The Black Box Revisited}

As the prime research paradigm in psychological animal research, Skinnerian behaviorism merits brief review, if for no other reason than to understand the theoretical and methodological floor the system stands on.

Learning theory has its roots in the work of the Russian physiologist, Ivan Pavlov (1849-1936). While studying the digestive process in dogs, he discovered that if a stimulus (A) which naturally produces salivation is consistently paired with a stimulus (B) which has no natural salivation-eliciting properties, (B) eventually will produce salivation even in the absence of (A). From this base, Pavlov refined the technique to identify factors such as unconditioned stimuli, conditioned stimuli, the effects of contingency (order), higher-order conditioning, extinction, stimulus generalization, etc., in a system which came to be known as classical or respondent conditioning. During the course of studies on stimulus discrimination, Pavlov produced an "experimental neurosis" in a dog required to make increasingly difficult discriminations between a circle and an ellipse.

The term "behaviorism" was coined by the American psychologist, John B. Watson (1850-1907). Dissatisfied with the introspectionist approach 
of his day, Pavlov's classical conditioning paradigm seemed to Watson to promise a means by which the scientific study of psychology could be accelerated by concerning itself only with observable stimuli and responses. Edward L. Thorndike (1874-1949) expanded upon this approach in his "Law of Effect," which on the basis of animal studies, proclaimed that learning can take place without reason, insight or understanding.

B.F. Skinner (1904- ) renamed Thorndike's Law of Effect "the principle of reinforcement" and studied the effects on animals' learning which are determined by the consequences of their behavior, i.e., operant or instrumental conditioning. Utilizing rodents and pigeons, Skinner explored various operant factors such as positive and negative reinforcement, escape conditioning, punishment, avoidance conditioning, shaping of behavior, chaining of behaviors, and the effects of various schedules of reinforcement. Skinnerian behaviorism is a "black box" approach in that the psychologist's task is to describe behavioral input into the organism (stimulation and reinforcement) and the resulting output (responses and behavior). The strict behaviorist, such as Skinner, sees no need to speculate about the inner workings of the organism, preferring instead to carefully record the observable consequences of various experimental conditions. Behaviorists employ the classical methods of experimental psychology to ascertain the concomitant variation among variables, such as the effects of various treatments on subsequent responses, or response-reinforcement relationships.

Segal and Lachman (1972) have noted that the behavioristic paradigm is grounded in the philosophy of Logical Positivism, a movement which emerged from Vienna in the 1920s. In very simplified fashion, this school believed that all sentences could be classified as: (1) analytic (logical; true by definition); (2) synthetic (belonging to science and verifiable by empirical observation); and (3) nonsensical. Radical behaviorists purport to investigate only "synthetic" issues and reject the direct study of subjective experience because it does not meet their criterion of verifiability. Science must be a public phenomenon, they argue, based upon strict observable methods capable of replication.

Another philosophical underpinning of behaviorism was referred to by Skinner (1975), "The issue is, of course, determinism.... I suggest that the spontaneous generation of behavior in the guise of ideas and acts of will is now at the stage of the spontaneous generation of life in the form of maggots and microorganisms 100 years ago."

Behavior, asserts Skinner, is no more "free" than digestion or any other physiological process. Behavior is caused by our environment (including environmental reinforcement history) not by alleged "free will." The principles learned about our overt behavior can be extrapolated to explain our covert behavior as well, without unnecessary reference to hypothetical subjective states, cognitions, or metaphysical constructs. 
Endler and Magnusson (1976), among others, have referred to the behavioristic approach as "situationism." They note that little attention is given to biological or inherited factors in this model, which prefers rather to focus on social learning processes. Behaviorism is thus biased toward empiricism as opposed to nativism.

Another essential facet to realize about the behaviorist approach is its goal from the scientific inquiry, namely to predict and eventually control behavior (Wertheimer 1972). From this angle, if a behavior cannot be successfully predicted, it has not really been understood. The principle of operant conditioning is intended to help predict behavior by demonstrating how new responses are shaped from simple movements through control of the consequences of those movements, i.e., getting positive or negative reinforcement. Furthermore, principles such as operant conditioning can only be developed from inductive, empirical investigation.

Skinner and his followers came to believe that the complex psychological processes of man could be reduced to principles or subcomponents essentially present in "lower" mammals. The conditions of learning were presumed to be the same across species. This position appeared reasonable at that time and received support from comparative anatomy and the reductionist positions of physiology and biochemistry (Segal and Lachman 1972). A classic illustration of the rampant optimism characteristic of early behaviorists can be seen in the concluding passage of Keller and Schoenfeld's (1950) Principles of Psychology, a popular text which appeared around the zenith of American behaviorism, "In a science that takes the whole of behavior as its province, what part of man's activities shall be said to lie out of bounds and exempt from scrutiny? Who can justly deny her the right of passage through any meadow, and on what basis declare that she trespasses?"

\section{The Case for the Opposition}

Spokespersons for psychological research with animals have responded to criticism basically by rejecting it. King (1984), Chairman of the APA's Committee on Animal Research and Experimentation (CARE), has flatly stated, "Basic psychological research with animals has led to important achievements in the interest of human welfare."

Rajecki (1983) asks, then answers a key question, "Whether or not one is correct in speaking of animal and human behavior in the same breath, has there been any real impact of animal data on general advances in modern psychology? Actually, there are quite affirmative answers to my rhetorical questions." Rajecki cites four examples, two from child psychology and development (infantile attachment and domi- 
nance relations among peers) and two from clinical/experimental psychology (learned taste aversions for the treatment of alcoholism and learned helplessness for the study of depression). We will later return to these and other examples of well-publicized research for more analysis.

Perhaps Miller (1985) has provided the most extensive defense of animal research in psychology. Miller's abstract cites the following list of animal research benefits:

...treatment of human urinary and fecal incontinence; psychotherapy and especially behavior therapy and behavior medicine; rehabilitation of neuromuscular disorders; understanding and alleviating effects of stress and pain; discovery and testing of drugs for treatment of anxiety, psychosis, and Parkinson's disease; new knowledge about mechanisms of drug addiction, relapse, and damage to the fetus; treatment enabling extremely premature infants to gain $47 \%$ more weight and save $\$ 6000$ per child in hospital care; and understanding mechanisms and probable future alleviation of some deficits of memory that occur with aging (p. 423).

Other areas mentioned by Miller include: principles of learning and behavior (classical conditioning, operant conditioning, motivation, reinforcement, drive, etc.), automated training devices, visual learning and biofeedback, effects of noise, effects of early experience, and prevention techniques. With reference to the latter area, Heffernan and Albee (1985) appear to reserve credit, not simply for the past achievements of psychology, but even for future ones, "When prevention activities in health and mental health are firmly in place, it will have been psychological expertise that is needed to answer prevention's central question: How do we change behaviors and attitudes?"

Simultaneous with articles such as those cited, the APA's CARE committee has been busy at work producing "exemplars" and explanations of animal research in psychology. Many of these papers were widely distributed at a recent APA convention (Toronto, 1984). One particular brochure entitled, Behavioral Research With Animals asked the rhetorical question, "Why is behavioral research with animals so important?" (side 1) to which the following reply is provided:

Research psychologists are both explorers and verifiers. They reach into the unknown in search of answers which must be tested and verified against real life conditions. Verification is the crucial step that separates truth from error. Humans are the focus of most psychological research experiments. But in seven or eight percent of behavioral investigations, animals are the focus of study. Animals are complex enough and similar enough to us to be informative not only about themselves but about human nature (side 1).

Whether the case for the opposition represents balanced and responsible scholarship or merely "behavioral bravado" is the question to be examined in the next two sections. 


\section{Theoretical Thin Ice}

Before reviewing the empirical track record of behavioral research with animals, it will be wise to dissect its rationale. Ulrich (1985, unpublished paper, "Animal Research and the Utopian Dream;" himself a former animal researcher widely published in the area of aggression), restated the fundamental premise, "The assumption that animals and humans are alike has been the cornerstone upon which scientists have built their rationale for laboratory experimentation." Singer (1975) put forth what has come to be known as "the psychologists' dilemma," "The researcher's central dilemma exists in an especially acute form in psychology; either the animal is not like us, in which case there is no reason for performing the experiment; or else the animal is like us, in which case we ought not to perform an experiment on the animal which would be considered outrageous if performed on one of us."

Rollin (1985) underscored the matter in noting that:

... at least some animal research in psychology is predicated upon the assumption that the animal mind or animal behavior is a good model for the human mind or behavior... And if the animals are to be adequate models for research into the effects of pain, pleasure, fear, anxiety, grief, depression, addiction, hopelessness, helplessness, and other mental modalities, or for research into such phenomena as learning, problem-solving, aggression, and mothering, the assumption obviously must be made that these states or behaviors are fairly similar in animals and in humans. If animals do not approximate the humans in their ability to experience such states, why use them? However, if animals are sufficiently similar to humans to be good models, what right do we have to do to them what we would not do to humans? (p. 925).

An immediate paradox comes to light. On the one hand, contemporary psychology implicitly (when not explicitly) accepts the cultural dogma that there are vast qualitative differences between humans and other animals. These differences are presumed to be especially great in dimensions traditionally of a psychological nature; e.g., intelligence, rationality, cognition, motivation, etc. On the other hand, the presumption of strong similarities between human and animal psychology constitutes the scientific basis for using "animal models" of human experience in the first place. What better illustration might one have of (to use an intentional play on words) "having your animal and eating it too."

In the past twenty-five years, numerous authors have offered reservations and objections to the behavioristic approach. Shapiro (1982) expressed the basic two-part objection to the animal researcher's rationale, "The use of these animal models is 'twice removed' from the phenomenon: First, the subjects are not humans; secondly, the animals are not themselves, i.e., they are themselves reared in artificial environments and subjected to artificial conditions. Any gain in precision and 
control is likely offset by losses through extrapolation across species and from artificial to natural environments and conditions."

Elsewhere, Shapiro discussed in more detail the problem of extrapolating from animals in laboratory environments to humans in real world settings:

On the laboratory side, clearly we no longer see other animals as simple organisms that somehow consist of certain states such as hunger or deprivation, states readily controlled, measured, and analyzed in the laboratory setting. When we divorce these or any animals from their natural habitat and from what we now are only beginning to learn of their natural social organizations, their patterned behavior, their communication, and their various adversarial, parasitic, and reciprocal relations with their environment and other species, do we really believe we have any idea of what we have a measure? On the clinical side, in most quarters it is no longer held that human psychopathology... is intelligible as a disease entity, certainly not that group of infectious diseases which partially prompted the animal model research strategy. It is not a matter of infecting another species with a human disease, then to follow and eventually affect its course. Even that limited part of human psychopathology that might be attributable to constitutional or neurological defect does not express itself in physiological symptoms that are straightforward signs of a certain disease. Our disorders are not diseases so much as they are at base peculiarly human phenomena, inseparable from culture and history, from language and meaning... (p. 5).

Mahoney (1977) noted that the key behavioral concepts are notoriously difficult to operationally define beyond the laboratory context; e.g., stimulus, response, reinforcement, behavior, environment, and learning. Fletcher (1984) voiced a similar concern, "In this fashion, Skinner attempts to purge commonsense language of mentalistic terms, purportedly producing a tight scientific discourse. I say 'purportedly' because one of the major criticisms leveled at Skinner concerns the status of these behavioral translations; namely, that although Skinner's concepts, such as reinforcement, are defined in a precise enough way in the laboratory with rats and pigeons, their meaning becomes crass and undifferentiated when applied to human social relations."

Influential critics such as Chomsky $(1959,1968)$ and the Transformationalist school of linguistics argued that because of man's capacity for rule-following behavior and creative language use, there was a great gap between "lower" animal conditioning and human learning which could not be bridged by generalization. On this theme, Shotter and Gauld (1971) commented, "The total failure of 'empirical' and neobehaviorist theories to handle even concept possession augurs ill for any 'empirical' theory of rule-following behavior.... The inability of 'empirical' theory and of traditional empirical methods to cope adequately with our linguistic abilities and performances thus emerges 
as only a part (but a central part) of their general inability to cope with human rule-following actions."

As one moves along the animal continuum from pigeons to people, reinforcement principles progressively explain less and less about organismic behavior (Smith 1978). It has already been demonstrated (Brewer 1974; Weimer and Palermo 1974) that the principles of conditioning are not equal to the principles of learning. Despite these commonplace objections, Bannister (1981) noted that:

\footnotetext{
Strangely, the theoretical assumptions underlying this vast undertaking have rarely been debated. The vast mass of animal work in psychology is published as if its fundamental value were unquestionable and only its detail needed to be examined (p. 307).... If the assumptions underlying animal experimentation in psychology are, at best, highly questionable, then how does it come about that they have not frequently been questioned? It may be due to the fact that the massive stream of published work in the field of animal experimentation is presented in such a way that its assumptions are deeply inferred within it, are so implicit that they neither arouse, nor are they readily accessible to, questioning (pp. 310-311).
}

Sometimes the theoretical import of animal research to psychological issues is not even available for analysis. Any cursory review of comparative psychology publications reveal a large number of articles which seem more appropriately found in zoological or biological journals. One is not inclined to challenge their relevance to human psychology because they claim none, except by implication by appearing in a psychological journal. Bannister (1981) put it, "Only by crediting the psychologically vast and vacuous statement 'man is an animal' can we believe that it will cast light on the psychology of humankind." It would seem that, insofar as Skinnerian behaviorism is concerned, relatively little has changed in nearly ninety years. London (1972), borrowing from Franks (1969) and Lazarus (1971), noted that all of the principles behavior modifiers ever refer to can be reduced down to about "one and one-half principles," namely that learning depends on the connections between what you do and what subsequently happens to you.

The failings of radical behaviorism have been all the worse because of its dogmatic insistence that valid knowledge could only be achieved via this model, thus relegating other approaches to myth, delusion, and superstition (Smith 1978). The attitude toward quantitative analysis is an excellent illustration of the differences between behaviorism and humanism. Wertheimer (1972) wrote, "Quantification, particularly premature quantification, may yield a totally false picture of a person or a phenomenon." Formulas, functions, and frequency distributions are usually abstractions or statistical fictions which may not really characterize anyone or anything. Wertheimer has argued that, in a seemingly 
counter-intuitive way, it is the strict experimentalist who is most subjective in his/her research:

The phenomenon the experimentalist concocts in his laboratory may be nothing more than some artificial curiosity, some meaningless monstrosity whose relation to real-world events is remote indeed. It is the experimental scientist, says the intuitive clinician, who goes too far in imposing his views in nature, whose methods permit him to see only what he wants to see. The design of a study precludes certain events: the scientist deliberately blinds himself. Rather than permitting nature to speak to him, he presumptuously tells nature what it is he wants her to tell him and what channel she must use, irrespective of whether the channel is appropriate to what nature could tell him if he would only let her. Why impose your conditions on nature? Why not open yourself fully to whatever she is saying, in whatever form the message can come through? (p. 250).

The foregoing theme has been expressed by Gadlin and Ingle (1975) who urged, "We ought to begin with a reversal of the present emphases: psychology should initially address itself to phenomena, not methodology. Rather than selecting for research those phenomena suited to our methods, we ought to shape and develop our methods to fit phenomena." Koch (1969) pointed out that psychology, "was unique in the extent to which its institutionalization preceded its content and its method preceded the problem."

The critique of "method-oriented research" has been undertaken by numerous other authors (e.g., Maslow 1954; Giorgi 1970; Romanyshyn 1971; Bakan 1972; Kvale 1973). Indeed, Baron (1971) argued that the main criterion in past financial support for research was methodological sophistication, sometimes with little regard for the question being researched. In a similar vein, Smith (1973) wrote, "I only deplore the sterility of much ritualistic research that is guided more by fetishism for the trappings of science than by any inner light." Any study purporting to provide insight into human nature which ignores the flux, the flow, the originality and the creativity of personal experience has hopelessly handicapped itself. Even Skinner's rats lever-pressed spontaneously before operant conditioning was introduced.

Another basic theme in the humanist critique of behaviorist methodology is that human research is relational. By ignoring the relationship between the experimental subject and himself, the strict behaviorist violates his own criterion of objectivity. Skinnerians see their subject matter and their methods as independent of one another, but this dichotomy is not only questionable, it encourages the scientist to see his subjects as objects. This approach, it is argued, has negative repercussions for both subjects and researchers alike.

Demarest (1983) finds fault with those psychologists who fail to clarify their theoretical assumptions, "Unfortunately, most people in 
psychology do not explicitly state what their assumptions are when reporting research or formulating hypotheses. This can present problems because many times the implicit assumptions underlying a research program provide the theoretical foundation for interpreting and generalizing the results. Ironically, although most scientists are well aware that their observations of nature are determined in large part by tacit theoretical assumptions, few ever stop to consider what these assumptions are or how they came to hold them."

Although Skinner openly promotes an "atheoretical" orientation, even basic analysis of the operant conditioning paradigm is problematic. For example, the hallmark of an operant or instrumental response (as opposed to a Pavlovian or respondent response) is that it is "freely" emitted. The likelihood of repeating an operant response is said to depend upon its consequences, i.e., rewards or punishments. Clearly, a laboratory animal (in a Skinner a box, for example) cannot truly be said to be "freely" emitting operant responses in any way analogous to human operant behavior. First and most obvious, the animal is confined to the experimental apparatus and would likely escape if given the opportunity. Secondly, in order to motivate action, laboratory animals are typically deprived of some basic necessity (e.g., food, water, etc.) or coerced by aversive stimulation (e.g., shock, noise, etc.). Thirdly, the customary protocol of animal experiments is designed to radically limit the range of available activities and thus elicit highly artifical behaviors which are not part of the animal's natural repertoire. Fourthly, in terms of theoretical impediments, one cannot argue that: a) animals' operant behavior is reflective of "freely" emitted choices; and b) the animals do not possess "free will" and therefore are acting on instinct. One can't have it both ways.

The rapid rise since the 1970 s of behavior modification techniques employing cognitive elements, e.g., Beck et al. (1979), is evidence of the limitations inherent in strictly behavioristic approaches to human psychology. In this light, behavioristic aspirations for building an objective scientific psychology without a self-concept and other cognitive dimensions can be seen as a futile mimicking of the physical sciences, or as one wag put it, "physics envy." Psychology, hopefully, is regaining consciousness - as well as conscience.

\section{Social Blessing or Psychology Pie (In the Sky)}

Psychology ... is an amalgam of humbug, platitude, piercing intuition, naiveté, soaring flight of the imagination, dull dogma, incisive reasoning and sheer drivel. Hence a certain fastidiousness in deciding what to read and what not to read on the subject is not to be despised. A system for protecting the less wary who venture into the swampy zones 
of psychological literature may be commended to Psychological Librarians. Every text on the shelves of the psychological library should have inscribed on it the number of grains of salt to be taken when reading it, and on the library table an ample bowl of salt should be placed and replenished at regular intervals. (Anonymous)

In terms of practical psychological benefits to humanity, how important has animal research been? This is a short and deceptively simple question with no easy answer. Avid proponents and avid opponents alike are frequently inclined toward exaggeration and distortion.

There are a variety of ways to approach this issue. One preliminary might be to get an overview of psychology's contribution as a whole to society, including both animal and human research. While I share a general sense of pride in and respect for my profession, it must be acknowledged that by no means has the field achieved consensual acclaim. Pion and Lipsey (1984) noted that, "Many critics have argued that psychology has a less than impressive record in understanding and explaining human behavior, especially social behavior (e.g., Dunnette 1966; Koch 1969; Meehl 1978; Sarason 1981; Smith 1972)."

In summarizing the results of a nationwide survey of graduate students and faculty in psychology, Lipsey (1974) noted, "The issue that generated the most heat was social relevance, the demand that psychology involve itself constructively in the widespread social problems that beset society. A large majority of both students and faculty felt that the discipline should be contributing to the solution of social problems and an equally large majority felt that at present it was making no important contribution."

In a recent article, Kimble (1984) reiterated a familiar theme, "Psychology has an identity problem. After more than a century of official existence, it still lacks a coherent set of values, there is little harmony among groups of us who practice very different professions, and there is even debate over the definition of our subject matter... The disagreements have been around for so long, in such varied contexts, and expressed by so many different individuals with no indication that we are moving toward consensus."

This is not to suggest, of course, that psychology has contributed nothing (as some overzealous critics have contended). The point here is that, if the entire field of psychology (including human-based research) has been of less than dramatic utility, overinflated claims from the animal-based research lobby within the profession must be taken with the proverbial grains of salt referred to previously.

Another measure of the contribution from animal research in psychology is the percentage of publications in the two APA journals which publish such work. The 1983 figures are representative of the past several years. According to the APA Summary Report of Journal 
Operations, 1983, the Journal of Comparative Psychology and the Journal of Experimental Psychology: Animal Behavior Processes have a combined rejection rate of 62 percent. Rejection rates for social science journals tend to be high anyway, but in this area, that cold statistic may amount to a lot of animals which experienced pain and/or death in vain.

Another measure of the contribution of animal research in psychology is the historical trend for specialty fields of new psychology doctorate recipients. According to studies by the National Research Council and the National Science Foundation (Pion and Lipsey 1984), the percentages of newly awarded doctoral degrees in animal research specialty fields (experimental, comparative, physiological) has changed as follows: 30.7 percent (1966); 21.7 percent (1972); 18 percent (1975); 16.1 percent (1977); and 13.7 percent (1979-80). It would be hard to explain these findings, which reflect a steady decline in those psychologists entering animal research fields, in terms of a theory which ascribes monumental importance to animal research results. Indeed, the theory would predict the opposite trend.

Another consideration in this analysis requires a better differentiation of the global term "animal research." While some animal rights advocates have irrationally called for an end to all animal research in psychology, a more representative position of the animal advocate community is opposition to vivisection. Defined in a modern sense (c.f., the Encyclopedia Americana, International Edition 1974), the term vivisection is no longer limited to surgical interventions but refers to any traumatic procedure which gives a medical or psychological problem to a previously healthy animal (e.g., inflicting diseases, injuries, deprivation, restraint, fear, stress, etc.). This is an extremely important concept methodologically, ethically, and in terms of the case which needs to be made by either side of the controversy. For example, most animal rightists would not object to properly conducted clinical research with animals done for their own benefit, nor to noninvasive laboratory work which respected the biological and social needs of the animal subjects, nor to ethological research in natural habitats.

Failure to consider this differentiation leads to unnecessary confusion. Consider the work of Rajecki (1983) cited earlier. In discussing the value of comparative research in understanding infantile attachment, Rajecki cites two ethological reports (Bowlby 1969; and Ainsworth 1969) alongside the vivisection studies of Harlow (to be discussed elsewhere). In making the case for animal research in the area of dominance relations among peers, Rajecki cites three ethological works (Tinbergen 1951; McGrew 1972; and Deag 1977) along with an entire table of conclusions based solely on ethological studies (p. 81). This is, so to speak, the academic version of "bait and switch," i.e., making a case for animal vivisection by reference to nonvivisection research. 
Another method for assessing the social relevance of APA published animal research is to sample recent journal articles in light of APA's stated policy that, "Psychological studies are aimed at understanding and alleviating the behavioral and health conditions that are problems for human society and for animals themselves" (APA Backgrounder 1984). To test the genuiness of this claim, a review of APA publications was conducted for studies appearing in the first half of 1984. Highlights included:

Journal of Comparative Psychology

March 1984, Volume 98, Number 1

Page

3 Subject: how mockingbirds respond to recorded spring and fall mockingbird songs during the two seasons

35 Subject: social behavior of young rhesus monkeys raised either with a surrogate "dog mother" or plastic hobbyhorses

45 Subject: differences in the sexual behavior of two different species of male voles (a type of rodent) given access to one, two, three, or four females

66 Subject: differences in aggressive attack behavior of female golden hamsters permitted one vs. multiple "biting attacks" upon a smaller "target" hamster

91 Subject: "maternal" behavior of young male and female rats exposed either to rat pups or pup-sized rubber toys

100 Subject: the effect of reward levels on the learning and loss of learning behaviors of honeybees

Journal of Comparative Psychology

June 1984, Volume 98, Number 2

Page

119 Subject: learning behavior of blowflies subjected to a heart disturbance and a motor response elicited by an illuminated disk while in a dark room

137 Subject: development of species identification calls in wood ducklings

189 Subject: motion sickness in Japanese quail exposed to rapid body rotation on a $70 \mathrm{RPM}$ turntable and a conditioned aversion to fluid

219 Subject: responses of 200 male and female college students upon exposure to the smell of a male sex hormone from pigs

Journal of Experimental Psychology: Animal Behavior Processes

January 1984, Volume 10, Number 1

Page

1 Subject: the ability of rats to process two simultaneous events

30 Subject: the ability of rats to learn a string of information by "chunking" the material into sections

90 Subject: the influence of the predictability of a conditioned stimulus (light) to the orienting response ("what-is-it?" reflex) in rats 
Journal of Experimental Psychology: Animal Behavior Processes April 1984, Volume 10, Number 2

Page

138 Subject: the ability of pigeons to differentiate between complex musical sequences

168 Subject: the role of odor given off by rats exposed to inescapable shock on the escape performance of other rats later exposed to shock in the same setting

182 Subject: social transmission of learned pecking preferences in newborn chicks

221 Subject: The "startle reflex" in rats exposed to loud bursts of sound

Journal of Experimental Psychology: Animal Behavior Processes July 1984, Volume 10, Number 3

Page

273 Subject: time discrimination ability of rats exposed to various stimulus conditions

333 Subject: the ability of pigeons to discriminate between events that they cause and those that they don't cause based on time cues

The intent of the survey was not to critique the design or analyses of these specific experiments per se. The sole question in mind was the relevance of this recent work to significant social problems and issues. The survey (complete form available from the author) suggests that typical animal research published in APA's journals, while academically impressive, bear little or no relationship to society's health problems or practical therapeutic techniques. Indeed, it is of more than passing interest to note that such relevance was rarely claimed even by the investigators themselves. It comes as no surprise that animal psychologists have sometimes been suspected of "scientific eccentricity."

In a New York Times essay by Nicholas Wade ("Smart Apes, or Dumb?" April 30, 1982), the author reported on a contemporary Psychology Today article in which "eleven of the best minds in the field" were surveyed as to their opinions on the most significant work in the field in the previous fifteen years. Wade noted:

Several contributors mention experiments of their own. Well, if they think that, there is no need for false modesty. But no work is cited by any other Best Mind except for purposes of criticism; each trumpet blower blows his own tune, which makes for a conspicuous absence of harmony. The failure of the 11 psychologists to agree on almost anything evinces a serious problem in their academic discipline. Physicists or biologists asked the same question would not concur on everything but there would be a substantial commonality in their answers. Can psychology be taken seriously as science if even its leading practitioners cannot agree on its recent advances?

To bring the phenomenon closer to home, I compared the reference lists for two recent and extensive papers, referred to earlier, both written for the explicit purpose of demonstrating the value of animal research in 
psychology: Rajecki's (1983) review chapter entitled, "Successful Comparative Psychology" and Miller's (1985) review article entitled, "The Value of Behavioral Research on Animals." Rajecki listed ninety-four references and seventy-eight authors. Miller listed one hundred and eighteen references and ninety-five authors. Cross-referencing the papers, I found only one common citation and only four common authors (neither Rajecki nor Miller mentioned the other's work).

As the longer and more recent article, I then compared Miller's (1985) reference list with the combined five-volume reference lists of the 1985 Association for Advanced Training in the Behavioral Sciences (AATBS; arguably the best and most comprehensive course for the national licensure exam in psychology). Of Miller's one hundred and eighteen specific citations (hand-picked to demonstrate the critical value of animal research to psychological knowledge), only seven (5.9 percent) could be found in the massed AATBS references. Of Miller's ninety-five authors, only seventeen (17.9 percent) were also noted by AATBS. To an impartial observer, this might lead one to conclude that Miller's reconstruction of the history of psychology placed undue emphasis on the role of animal research.

Perhaps the most convincing empirical evidence that Miller and his colleagues have greatly inflated the importance of animal research to the development of therapeutic psychological techniques comes from recent research by Kelly (1985). Kelly conducted a detailed examination of all reference citations appearing in every article published by the Journal of Consulting and Clinical Psychology (JCCP) and Behavior Therapy during calendar year 1984. These two journals, both rigorous in their publication standards, were chosen because treatment research topics represented in their 1984 volumes coincide with those areas touted by Miller (1985) as most indebted to laboratory animal research. In 1984 (Volume 52), JCCP contained a total of 3,293 reference citations to the work of others. Of these, only ten (or less than one-third of one percent of the total) were citations of laboratory animal studies. Indeed, only nine of the 164 articles published by JCCP contained any references at all to animal research. In 1984, Behavior Therapy (Volume 15) contained a total of 1,132 reference citations. Of these, only twenty-three (or two percent of the total) were citations of laboratory animal studies. Only six percent of the articles published that year in Behavior Therapy contained any references at all to animal research.

Based upon these empirical findings, Kelly concluded:

Miller argues that treatments for a myriad of clinical disorders in humans depend critically on laboratory animal research. However, clinical researchers who publish in these two high-quality journals rarely cite animal studies. If we assume that researchers reference those previous studies that they deem most critical to their own work, it is evident that Miller's conclusions are inaccurate.... Moreover, as 
confirmed by my reference citation study, most current clinical interventions, including behavioral interventions, for the human disorders described by Miller depend far more closely on previous behavioral research with people rather than animals (p. 3).

Before examining specific examples of research cited by Miller (1985) in terms of the level-of-benefit claimed, a fundamental point of clarification is in order. It is not enough for the vivisection proponent to cite clinical techniques which utilized animals at some stage of development; one must also make the case that such use of animals was indispensible. I do not establish the "necessity" for a carnivorous life-style merely by showing that animal flesh has been a major source of protein and fat in the human diet. Drewett and Kani (1981) expressed this idea as follows:

Whether behavioural research on animals is responsible for clear substantial advances in clinical practice that could not be attained without it is something that is more difficult to assess. The rider is important. The critical question, for those who wish to make a serious attempt to reduce the number of animals used in experimental work, is not whether research on animals makes a contribution, but whether it makes an indispensible contribution.... But it would be curious to argue that it would have been impossible to carry out the relevant research on human subjects; for how could a therapeutic method for use with human beings be based on principles of learning which could be demonstrated and investigated in dogs and rats, but which could not be demonstrated and investigated in human volunteers? Indeed, one could argue that the development of behaviour therapy might have been more rapid if more of the relevant research had been carried out on human volunteers rather than on animals (for instance, the importance of imagery would probably have been defined earlier) (pp. 196-197).

To cite another analogy, the statement, "Ninety percent of the transportation benefits enjoyed by people in the last century are attributable to the exploitation of fossil fuels," may be a factual historical assertion, but this obviously does not prove that transportation benefits required this type of technology. Given the massive exploitation of animals in psychology, the truly surprising observation is that so much basic knowledge and practical advances remain elusive. The point here is that a statement such as, "X and Y necessitated the use of animals," is a decidedly nonscientific claim. Ultimately, the only way to empirically demonstrate such an assertion is to do the impossible, i.e., turn back the clock and proceed along alternative research lines to determine the level of achievement possible. This obviously cannot be done, therefore such claims are not subject to scientific confirmation or refutation. Such assertions must be recognized as politically motivated speculation.

A comprehensive review of the proclaimed benefits of behavioral research with animals is clearly beyond the scope of this paper. In all of the following sections, primarily based on Miller's (1985) report, it must be acknowledged that significant and sometimes substantial 
advances have been made in all of the areas mentioned. Nevertheless, the following is intended to raise legitimate questions about the level of benefits claimed or implied.

\section{Principles of Learning}

There is no debate that the use of animals was instrumental in this area, but there is no convincing evidence that animals were absolutely essential. For example, did Pavlov require the use of dogs to demonstrate the principles of respondent conditioning? This seems implausible given the fact that, "Classically conditioned responses have been established for a variety of other subjects including human beings" (Mancucella 1984). Indeed, classically conditioned responses (which are not under voluntary control) can be established on resistant, drugged or even unconscious subjects. Likewise, there is no clear evidence to suggest that Skinnerian or operant principles of conditioning could not have been explored using human volunteers. As discussed previously, the concept that operants are "freely emitted" breaks down in the case of laboratory animals which are confined, deprived, coerced, and given an artificially restricted range of possible behaviors. Even Skinner (1975) has bemoaned the futility of trying to apply laboratory-derived principles to the human condition, "Why has it been so difficult to be scientific about human behavior? Why have methods that have been so prodigiously successful almost everywhere else failed so ignominiously in this one field?" As Smith (1978; past president of APA) put it, "Behaviorism has had a full and fair chance over more than half a century to show its worth; it has failed."

\section{Treatment of Enuresis}

The work of Mowrer and Mowrer (1938) in development of the "bell-and-pad" technique is said to be based on learning principles derived from animal experiments, but again, no compelling evidence is presented to show that the former depended upon the latter. Indeed, Azrin and Thienes (1978) have found that a treatment without a conditioning apparatus which involves training in rapid awakening, correct toileting, and social reinforcement for nonenuretic behavior is even more effective.

\section{Automated Training Devices}

The claim is made by Miller (1985) that teaching machines and programmed learning were dependent upon animal research. As before, it strains the imagination to suggest that such approaches necessitated the use of animals, particularly considering the qualitative differences in learning which apply to human subjects. In any event, such devices are hardly a panacea. As Mancucella (1984) noted, "In spite of the fact that programmed instruction has proven to be a useful tool for certain kinds of learning and in certain situations (e.g., in teaching material 
to large groups of students), it has several drawbacks: Students often dislike working with machines, programmed instruction tends to limit teacher-student and student-student interactions, and, especially in the case of computerized program instruction, costs can be prohibitive."

\section{Behavioral Therapy}

The term behavior therapy encompasses a wide variety of therapeutic techniques. A widely accepted definition of the term provided by Yates (1978) was referred to by Becker (1984):

Note that Yates' definition makes no specific reference to learning theory as the only underlying basis of behavior therapy. Instead, Yates has provided a definition which describes the unique, systematic approach taken by behavior therapists in attempting to understand and treat a variety of behavioral problems (p.7).... One of the first major contributors to the future field of behavior therapy was William James. As early as 1890, James included a chapter on habits in his textbook Principles of Psychology. This chapter set forth many of the principles which are still considered essential to the practice of behavior therapy (p.3).

The point here is that behavior therapy as currently defined and practiced can hardly be said to be a direct application of learning theory based on animal research. Indeed, behavior modification techniques currently most in use are increasingly reliant upon cognitive factors which strictly traditional respondent or operant conditioning ignored (e.g., rational-emotive therapy, Ellis 1962; cognitive restructuring, Meichenbaum 1973; anxiety management training, Suinn and Richardson 1971; stress inoculation, Meichenbaum and Cameron 1973, etc.)

Recognition of the limitations of "animal models" of human neuroses, phobias, and obsessions has long been noted. Consider, for example, the observations of Marks (1977), Kubie (1939) and Hunt (1964), respectively:

A major problem encountered in conditioning experiments on fear acquisition is that clearly traumatic events-a definable US (unconditioned stimulus) - can rarcly be pin-pointed at the start of human phobias and obsessions... Because there is usually no history of a clearly traumatic onset to human phobias or obsessions, we cannot assume that they have been conditioned, only that they have been acquired. Traumatic conditioning is uncommon in humans, and experiments on this issue are understandably rare. In a typical animal experiment, a single CS (conditioned stimulus) and a single US are arranged to produce fear. In contrast, a variety of situations usually trigger a patient's clinical distress, and those are seldom traceable to particular traumatic experiences. No one knows the original US, or if indeed one ever existed. The phobia or obsession simply appears, and search for the equivalent of unconditioned shock is fruitless (p. 204, 207).

The dream of the scientist in the field of psychiatry is to find an equivalent of Koch's postulates. His despair has been the impossibility of translating the voice and behavior of lower animals into anything 
comparable to the symbolic language of Homo sapiens. This has limited the significance of efforts experimentally to produce neuroses in laboratory animals; because language is necessary for the communication of ideas, without which nothing comparable to a human neurosis is conceivable... The experimentally induced disturbances in animals are quasineuroses, not in any true sense indentical with human neurosis (p. 541).

Despite all this promise and appeal, the animal neurosis experiments seem not to have amplified our knowledge about human psychopathology materially. More characteristically, these experiments receive favorable attention because they illustrate, duplicate, or confirm things already known about the human case. While illustration and confirmation are not trivial contributions, we must ask why this comparative sterility? (p. 28).

While behavior modification techniques offer hope in the treatment of human psychopathology, one must always be on guard against excessive claims. Case in point: Miller's (1985) reference to Wolpe's (1976) optimistic report entitled, "How laboratory-derived principles of learning have conquered the neuroses." The writers of the Diagnostic and Statistical Manual of Mental Disorders III (DSM III, 1980) found a more expedient solution by dropping the term "neurosis" from its current classification scheme, primarily due to a general lack of consensus among clinicians on the term's definition.

\section{Behavioral Medicine}

The extension of psychological treatment into areas traditionally associated with the practice of medicine is a promising new development. Yet, as always, one would do well to consider claims from scientists which may be more politically based than scientifically based. As an antidote to the former, I offer the following commentary by Kaplan (1984b):

The expected health benefits from behavioral programs may not match the enthusiasm espoused by some health psychologists.... As an enthusiastic supporter of health psychology and behavioral medicine, I am pleased to see the field developing and thriving. Yet, the art should not precede the science. The rationale behind many applications in health psychology depends on a series of as yet unverified assumptions (p.755).... In the following sections, I will argue that these and other assumptions in the clinical practice of health promotion are not uniformly supported by research data. As a result, we are in danger of losing credibility by overenthusiastically announcing the expected benefits of our services (p.757).... My only concern is that we recognize the complexities of the problems and the general absence of definitive evidence on the relationship between behavior interventions and disease prevention. There is no quarrel with health promotion, only with the promotion of health promotion (p. 763).

\section{Biofeedback}

The work of Miller $(1978,1980)$ was highly important in demonstrating that human subjects could alter autonomic responses (salivation, blood pressure, temperature, heart rate, etc.) when given systematic 
performance feedback on their physiological status and selective reinforcement. This technique, which represents aspects of both classical and operant conditioning, has been applied to a wide variety of physical ailments. Once again, one is frustrated in the search for convincing evidence that this technique depended upon prior animal research. For example, Miller (1985) cites the human subjects research of Basmajian (1963) on the firing of single motor units and work of Kamiya (1969) which examined the voluntary control by human subjects of EEG rhythms. Miller then asserts, "But these two types of human behavioral experiments were dependent on earlier physiological experiments with animals that studied the electrical activity of nerves and that discovered the existence of single motor units." Why, one might reasonably ask, is this the case? It can hardly be argued that human volunteers would have been exposed to excessive risks, nor can it be suggested that the efficacy of biofeedback techniques depends upon the subjects' comprehension of the physiological mechanisms involved. In fact, successful biofeedback subjects typically cannot even articulate how they voluntarily elicit changes in their physiological functions.

On the clinical level, the successful application of biofeedback has been moderate at best and carries practical disadvantages. Becker (1984) took note:

Initial enthusiasm for biofeedback has, however, diminished somewhat due to mixed research results and practical shortcomings. In terms of research results, one of the initial claims concerning the use of biofeedback was its ability to enhance the production of alpha waves which have been associated with states of euphoria and relaxation. Subsequent research has, however, shown that biofeedback is not necessarily a reliable method for increasing alpha waves (e.g., Plotkin and Cohen 1976). Additionally, it has been found that some individuals have great difficulty learning to regulate physiological responses. Finally, the use of biofeedback not only requires a large monetary investment in equipment, but also extensive technical knowledge to use such equipment (p. 34).

\section{Effects of Stress}

After acknowledging that clinical and epidemiological work (and hopefully some common sense) has indicated that stress can exacerbate a wide variety of medical disorders, Miller (1985) discussed a number of animal studies, "in which confounding factors can be rigorously controlled." This is arguably tunnel vision in that he presumes that captive, manipulated animals experience no stress other than that experimentally provided by the investigator. He specifically cites research summarized by Henry and Stephen (1979) on a mouse colony where the animals were forced to compete for food, water, and space. Miller concluded that these experiments provide a good animal model of "psychosocial stress." In my judgment, it is scientifically hollow (not to mention ethically reprehensible) to expose animals to hellish conditions 
and then analytically observe that they deteriorate into hellish behavior. Even in terms of the applicability of such work to human populations, Gangsei (1983) observed:

The detrimental effects of overcrowding among animals was demonstrated by Calhoun (1962) who found that increased population density in a population of rats resulted in a variety of pathological behaviors (e.g., reduced fertility rates, increased mortality rates, sexual aberrations and increased aggressive behavior). Several mental health researchers have similarly investigated the effects of increased population density on human behavior. Unfortunately, the results of human research, although suggesting the existence of an important relationship between population size and behavior, have been less consistent than those obtained in animal research (pp. 9-10).

Miller (1985) contends that animal experiments "are demonstrating a point-to-point correspondence between the after-effects of unpredictable, uncontrollable electric shocks and the behaviors characteristic of human depression as described in the latest manual for psychiatric diagnoses, Diagnostic and Statistical Manual of Mental Disorders (DSM III; American Psychiatric Association, 1980)." This rather remarkable conclusion is disconfirmed elsewhere in the literature on learned helplessness and uncontrollable stress. Rajecki (1983) observed (sadly):

Alas, despite their valuable contributions in the past, the place of dogs in future learned helplessness research is doubtful. The original theoretical formulation for helplessness effects was that a lack of contingency between response and outcome led to a reduction in the incentive for operant responding (Miller et al. 1977). By now, this relatively simple hypothesis has been supplanted by a more complicated formulation that incorporates ideas of (for example) universal versus personal helplessness, general or specific helplessness, whether future helplessness will be chronic or acute, and whether it will lower self-esteem or not (Abramson, Seligman and Teasdale 1978). Many features of the newer formulation rest on cognitive and attributional processes that are not usually associated with dog behavior. Indeed, Abramson, et al. (1978) state that: "Investigators of human helplessness ... have become increasingly disenchanted with the adequacy of theoretical constructs originating in animal helplessness for understanding helplessness in humans. And so have we." (p. 102).

Even more discouraging is the report from Mineka, et al. (1984):

Over the past 15 years an enormous amount of research has been directed toward understanding the differential behavioral and physiological effects that stem from exposure to controllable as opposed to uncontrollable aversive events. The general conclusion has been that exposure to uncontrollable aversive events is considerably more stressful for the organism than is exposure to controllable aversive events. The greater stress has been indexed by a wide range of behavioral deficits and physiological changes, including impaired ability to learn control in subsequent tasks, passivity, lowered aggressiveness, alterations in levels of certain important neurotransmitters, ulcers, 
analgesia, and many others (p. 307).... Nevertheless, we believe our results are important in highlighting the importance of two issues. First, they raise some question about the validity of the conclusions of the hundreds of experiments conducted over the past 15 years or so that have compared the effects of controllable versus uncontrollable shock on a variety of dependent variables.... The second issue highlighted by our results concerns the importance of examining the dynamics of fear conditioning in more complex contexts than those in which it has traditionally been examined (p. 322).

It is no wonder that Pratt (1976) bemoaned, "On this obsessive study of terrorized small animals the cumulative outlay of public funds has been enormous, even though the research can hardly claim relevance to human problems."

\section{Pain}

Miller (1985) illustrates the classic mixed message of the animal research advocate in contending both that, "Considerable progress has been made in controlling pain ... [and] chronic pain is the most costly health problem in America." Unfortunately, it is not difficult to document the low payoff from the massive volume of pain research on animals. A leading expert in the field (Lineberry 1981) soberly observed:

The control of pain in humans has always been a difficult problem. As a consequence, considerable basic research on pain has been conducted on laboratory animals, but the results have provided few consistently effective weapons for the physician. Despite a recent resurgence of interest in pain mechanisms, research efforts have thus far failed to achieve a level of understanding that even begins to approach our knowledge in other sensory systems. Thus, efforts to devise new and effective treatments for pain have generally failed (p. 238)... The situation is perhaps even more complicated in animal subjects, since, in nonhuman subjects, it is not possible to obtain verbal subjective reports (p. 240)... The pain literature is filled with hundreds of different techniques... for measuring responses to noxious stimulation in animal subjects (p. 250).... It is obvious that no method available is without serious limitations (p. 251)... One cannot with absolute certainty conclude that a stimulus is either painful or not painful on the basis of the probability of that stimulus eliciting an escape response (p. 273)... . One cannot, therefore, with confidence describe reductions in response to noxious stimuli as analgesia.... This is an old problem in analgesic testing, with no evident solution given the experimental techniques available at the present time (p. 274).

The infliction of pain in laboratory animals will be discussed further in this paper. Suffice to say that two monumental practical problems exist for the animal researcher in this area: a) knowledge about pain in animals is very rudimentary and still basically inferential; and b) there are serious problems in cross-species extrapolation of the effects of anesthetics, analgesics, and tranquilizers. 


\section{Behaviorally Active Drugs}

Levine, et. al. (1971) concluded, "During the brief history of treating psychiatric depressed patients with drugs, therapeutic efficacy has almost always been developed from clinical experience-usually by accident." Baldessarini (1975) noted:

The behavioral effects of drugs in the experimental situation was often very different from the effects observed clinically. An outstanding example of this phenomenon is that large acute doses of most anti-depressants tend to produce sedation in normal laboratory animals, and it has been very difficult to devise reliable laboratory behavioral tests to screen potential new anti-depressant drugs. Another problem is that most of the so-called "animal models of affective (mental) illness" are more nearly models of sedation or stimulation, thus making it very tricky to make predictions about human clinical responses based on animal behavior (p. 74)

Shapiro (1982) observed that, "Most of the 'major tranquilizers' which control some psychotic disorganization were discovered in human contexts, either clinical and epidemiological studies or 'accidental' discovery - not in animal studies."

Chlorpromazine (Thorazine) is given special notice by Miller (1985) as one beneficial by-product of animal research in the treatment of schizophrenia. This is a debatable attribution in view of the record that the phenothiazine class of drugs (of which chlorpromazine is the best known example) was used originally at the turn of the century as antibiotics (Kuker-Reines 1982). Chlorpromazine itself was initially developed for use as a sedative. Its "anti-psychotic" properties were not discovered until the early $1950 \mathrm{~s}$, and then by the use of astute clinical observation, not by laboratory research, even though (as always) efficacy was tested on animals. While there is no doubt that the use of chlorpromazine (and other psychoactive drugs) has made a major contribution in the symptomatic treatment of serious psychological disturbances, one must remember that such substances are palliative not curative. Furthermore, while chlorpromazine is not associated with the development of tolerance, dependence or withdrawal, the drug comes with a host of unpredictable, serious, and sometimes irreversible side effects.

\section{Effects on Early Experience}

Miller (1985) cites the animal work of Wiesel and Hubel (1965) as, "showing that various forms of visual deprivation or conflict between images from the two eyes causes permanent deficits in visual connections in the brain. As a result of this work, pediatricians are paying far more attention to the very early detection and correction of visual defects in infants."

In response to such claims, Drewett and Kani (1981) commented:

Such claims are now commonplace, yet it is difficult to see what new principle of clinical importance derives from these findings. The animal 
work originates with Wiesel and Hubel (1963) and Hubel and Wiesel (1965); but it was by then already well established in clinical practice that there was a critical period in the development of the human visual system.... Indeed, Wiesel and Hubel (1963) themselves point out that the difference between the effects of deprivation in kittens and adult cats is "a difference one might have expected from the profound visual defects observed after removal of congenital cataracts in man, as opposed to the absence of blindness on removal of cataracts acquired later in life;" and Hubel and Wiesel (1965) that, "it is recognized that squint in a child must be corrected in the first few years of life if capability of using both eyes in binocular vision is to be retained." So the fact that there is a critical period in the development of vision, and its clinical implication, that visual defects should be detected and corrected as early as possible, did not derive from this work on animals. It was already known (pp. 191-192).

A similar, and more disturbing, set of inflated claims is Miller's praise for the deprivation and social isolation research of Harlow, et al. (1965). Considered as a whole, it would be difficult to find a more traumatic series of experiments than those inflicted by Harlow and his associates at the University of Wisconsin primate laboratory. The "ingenious" (some would say diabolical) techniques Harlow used to produce extreme psychopathology are well known and need not be dwelled upon here. The best rebuttal to Miller's scenario that these researchers were humane individuals who advanced clinical understanding of child abuse is to let them speak for themselves. As Harlow once confessed in a moment of candor (Pittsburgh Press Roto, October 27, 1974), "The only thing I care about is whether the monkeys will turn out a property that I can publish. I don't have any love for them. Never have. I really don't like animals. I despise cats. I hate dogs. How can you like monkeys?" (Pratt 1976). Elsewhere, Harlow and Suomi (1977) addressed the question of the clinical relevance of this work:

Some researchers have pointed out the similarity between elements of the isolate monkeys' behavior and specific behavior patterns exhibited by autistic human children. Anyone who has had the opportunity to observe both autistic children and isolate monkeys would feel compelled to consider them as examples of similar phenomena-particularly with respect to stereotypic rocking activities. Does this mean that, keeping in mind the basic behavioral differences between the species, the social isolation syndrome in monkeys serves as an effective model of childhood autism? We doubt it. It is our belief that the social isolation syndrome in monkeys can serve as an adequate model for only one human disorder - the human total isolation syndrome.... If one could systematically separate human infants from mothers at birth and maintain them for the first two to four years in physical and visual isolation from other humans, the infants would probably exhibit the same reactions as monkeys reared in isolation (p. 145).

Of what use are the data obtained from depressed monkeys for clinicians currently working with depressed patients? We have a considerably 
more difficult time establishing a strong case [for such use] since so much monkey work to date has been based upon existing human data and theories (p. 173).

As with other behavioral research with animals, in my judgment, the Harlow experiments did not substantially advance clinical knowledge in the sense of providing new key concepts. Basically, they simply demonstrated that psychopathology in animals can be produced by the same factors already known or suspected of producing it in humans. At best, this type of research mimics and follows human research. At worst, as in this case, Harlow ironically reconfirmed the importance of love to personal health by utilizing gross abuse, demonstrating (some might say) a profoundly warped sense of what love is all about.

\section{Deficits in Learning and Memory with Aging}

Miller (1985) makes a case for using animals in work related to memory loss, as in Alzheimer's disease. The logic is curious in that animals are said to make good models of human aging because, "Many animals age much more rapidly than people — rats approximately thirty times as fast." Miller enthusiastically proclaimed, "These animal models of memory defects with aging are providing powerful means for analyzing experimentally some of the mechanisms... that play a role in the memory deficits."

As before, we would do well to broaden our search in the professional literature for a more sobering perspective on the utility of laboratorybased research in the field of memory. Tulving (1979) had this to say:

After a hundred years of laboratory-based study of memory, we still do not seem to possess any concepts that the majority of workers would consider important or necessary. If one asked a dozen or so randomly selected, active memory researchers to compile a list of concepts without which they could not function, one would find little agreement among them, particularly if one excluded terms referring to experimental operations and data. Similarly, if one compares different textbooks of memory, one discovers that there is little overlap among their subject indexes. It seems that important concepts of one author can apparently be dispensed with by another (p. 27).

Loftus, et al. (1985) recently noted that Neisser (1982) came to a similar conclusion:

Recently, Neisser (1982) registered his dissatisfaction with the orthodox psychology of cognition, and particularly with the study of memory. To him, the field has little to show for a hundred years of effort, perhaps because it always avoided interesting issues... The time has come, Neisser believed, to investigate questions of interest in more naturalistic settings. To paraphrase him, just as the naturalistic study of animal behavior has proved to be more rewarding than traditional research on "learning," so a naturalistic study of cognition may be more productive than its laboratory counterpart (p. 179). 


\section{Prevention}

Miller (1985) asserts that principles of learning (based on animal experiments, of course) have been "useful" and "helpful" in designing programs of primary prevention, specifically citing projects aimed at reducing the number of children who start smoking. To suggest that smoking is an area where animal research has led to "breakthroughs" in the clinical problem for people is more wishful thinking:

In spite of the documented dangers of smoking, 54 million Americans smoke tobacco (HEW 1976) and smoking therefore remains the greatest public health hazard in the United States. Unfortunately, no treatment technique has consistently been shown effective for the treatment or prevention of smoking. In fact, it has been estimated that only about one-half of smokers who participate in smoking cessation programs are able to abstain by the end of the program and, of these, only one-third continue to abstain during the following year (Hunt and Bespalec 1974). Interestingly, it has been estimated that $95 \%$ of the 29 million individuals who have stopped smoking since 1964 have done so without professional help (National Cancer Institute 1977) (AATBS: Abnormal Psychology 1984, p. 32).

\section{Sexual dysfunction}

Although not specifically cited by Miller (1985), this is an important area for obvious reasons. Drewett and Kani (1981) expressed some themes which can be constructively applied in this area as well as the others just reviewed:

What we think is remarkable here is the extent to which the very large body of behavioural work on animals has not had any major clinical pay-off in the treatment of human sexual problems. The research workers who have made major contributions here have been those pioneers who have worked directly on human sexual behaviour, particularly the zoologist, Kinsey (Kinsey et al. 1948, 1953) and the gynecologist and social psychologist Masters and Johnson $(1966,1970)$. It is certainly true that research on the sexual behaviour of mammals contributed to the early development of the field.... But we are inclined to think that psychologists and others who are now genuinely interested in advancing medical progress in this area ought to be working directly on the human case, and not on animals... What has been lacking has simply been a sufficient investment of time and effort. To some extent this may have been a result of too great a concentration on work on animals (p. 183).

\section{General Summation}

The preceding section offers no pretense of an exhaustive review. Among the lessons it does provide, however, are the suggestions that, like any special interest group, the vivisection lobby in psychology is prone to hyperbole in overstating the case, exaggeration of the clinical application of this work, and selective restructuring of the history of psychology for purposes of elevating animal research to a level of practical utility it does not merit. This is by no means a new conclusion. Heim (1979), Ryder (1975), Dalen (1969) and others have arrived at similar 
positions. Echoing the appeal of Drewett and Kani (1981), I would contend, "It is these same facts that ought, we feel, to make psychologists more unwilling than they are to carry out experiments that cause suffering to their animal subjects; here, as so often elsewhere, the most creative response to criticism may be to listen to it."

\section{The Psychology of Animal Psychologists}

Ironically, I have often found myself defending animal researchers from brazen accusations of "sadism" and of inflicting "torture" upon animals. Such characterizations are overly sensationalized and, in my judgment, simply wrong. I have too much respect for most of my colleagues in psychology and too much appreciation for the complexities of this issue to arrive at such a banal diagnosis. There are, however, important psychological factors at work here which should be discussed because they shed light upon the experimenter him/herself and thereby upon the issue in dispute.

Psychologists are generally adept at devising clever techniques to test hypotheses with great precision. Unfortunately, our training generally does not leave us very skilled at generating important or interesting hypotheses to test. Unlike other areas of research, psychologists cannot afford the pretense of being objective, detached observers. This is because, unlike the situation in the physical sciences, psychologists cannot turn a blind eye to their own behavior during the research process without ignoring the most direct psychological data available. In trying to mimic the physical sciences, psychology has seized upon the use of so-called animal models because, among other things, it facilitates the fictional gap between the researcher and the object of his/her research.

Bannister (1981) discussed this issue in terms of "reflexivity," i.e., self-awareness of the researcher as something more than a "detached," "objective" collector of data:

Animal psychology offers its practitioners a domain within which they can personally and publicly avoid the issue of reflexivity in all its forms. It has served as an undercover way of introducing and maintaining mechanical models in psychology because it is easy to be mechanistic about animals but more difficult to be mechanistic about one's fellow human beings. Not surprisingly, the current wave of humanistic psychology which insists that we see human... concerns, received much of its initial impetus from a rejection of "rat" psychology. Working within the socially remote world of animal experimentation has sheltered many psychologists from the kind of political questioning to which psychology is now rightly subject... Part of the urge to evade the reflexivity issue stems from a desire to mimic, in a concretistic way, the natural sciences: to earn for ourselves the title of "scientist" and be rewarded with the 
prestige attached to that title. Thus psychologists have sought the kind of "precision" which they see as being the hallmark of science. We have sought the appearance of precision by hiding tenuous argument behind elaborate, statistical design (quoting figures, whose conceptual referents are doubtful, to the third decimal place) and by using impressive instrumentation. However, so long as our experiments involve people, our peers, with their capacity to outwit and seduce us and to see beyond the experiment, then our precision is often set at nought. If we use speechless animals - our infinitely manipulable property - then we can achieve a kind of spurious precision: we can be precise within the confines of our experiment even though the wider implications of the experiment are enormously imprecise (pp. 314-315).

As the so-called "talking animal," it is also hard to overestimate the importance which language has on this insidious conditioning process. Consider, for example, the word "animal." The word itself is frequently used in a derogatory sense, to mean sub-human, filthy, or debased. The term "beast" is even more explicit in this regard. There are many other common examples where animal names are used intentionally as insults, e.g., pig, swine, vermin, rat, weasel, skunk, jackal, jackass, chicken, turkey, goat, wolf, snake, lark, bird-brain, bitch, ass, etc. If one looks hard enough, one will find samples of animal phrases used in a complimentary way. For example, "wise as an owl," "brave as a lion," or "busy as a beaver." But for every such example, many more counter-examples which reflect the rule are to be found, e.g., "shouldn't happen to a dog," "go ape," "stubborn as a mule," "crocodile tears," "this place is a zoo," "crazy as a loon," "smells fishy," "dumb bunny," "bullheaded," etc.

As Bowd (1980) has written, the specialized vocabulary of experimental psychology is also an important factor in creating and maintaining attitudes toward laboratory animals. There is a certain hygienic illusion in using euphemisms like "organism" or "model" instead of dog, "aversive stimulus" instead of punishment, "deprivation" instead of starvation, "phonate" instead of scream, "agitate" instead of struggle, and "sacrifice" instead of kill. Ironically, it is generally considered unscientific and anthropomorphic to attribute emotional or intellectual states to laboratory animals, even though the very rationale of psychological research presumes that the causes of animal behavior are analogous to the causes of human behavior. Consequently, in the psychological literature, one often sees words like pain, fear, intelligence, insight, sadness, curiosity, etc., placed within inverted commas. This is supposed to signify that these words should not be taken literally, but rather are needed to avoid the inconvenience of trying to describe animal behavior without any reference to the animal's subjective experience. The net effect of the customary linguistic style in the scientific literature is to maintain a nonscientific distinction between human animals and nonhuman animals. Set in the context of prevailing philosophical assumptions 
about animals (to be discussed elsewhere), such linguistic detachment allows the otherwise sensitized researcher to dispassionately discuss traumatic manipulations that would be considered heinous if performed on a fellow human being.

As an academic discipline, animal researchers-in-training or in practice are subject to not so subtle pressures noted by Bowd (1980), as follows:

In addition to language practices, psychology students are persuaded to accept prevailing attitudes toward animal research by a variety of social forces. Peer pressure and the attitudes of professors categorize squeamishness and sentimentality as unscientific, it being implied that such natural emotional reactions are irrational while the ability to suppress them is not. The graduate student who for ethical reasons may choose not to subject animals to painful experimental procedures may find fewer doctoral programs available. Finally, there are subtle prejudices within university psychology departments such that experimental animal research is frequently considered more basic and is invested with a prestige that is denied more applied study (p. 205).

Evasion of reflexivity, sanitized language, peer pressure and other factors often result in extraordinarily self-serving public posturing by the animal researcher. Even more important, the private self-image of such individuals is characteristically of similar quality. Lockwood (1984) made the following astute observations:

One of the reasons why the animal welfare movement elicits such a visceral response from the opposition is that we are challenging the self-image of many researchers. They have convinced themselves that they are the intellectual light and salvation, and whatever suffering they might produce is for the greater good of mankind. Bernard Rollin has summarized their view as "Leave me alone, I love my dog and I'm curing cancer." Often they have labored hard and long to build a shell of insensitivity that makes their basic routine possible. Frequently, I believe, these defenses have been constructed at great personal and social cost and we cannot expect them to be shed easily (p. 10).

One of the important insights of social psychology is that physical abuse is more likely to occur when the victims are anonymous and physically separated from their oppressors. Uniform-looking laboratory animals which are then isolated from the investigators foster such a situation. Utilization of sophisticated laboratory equipment has a similar impact. The original questions which promoted a line of research can be overshadowed by the techniques and hardware available for studying them. Speaking from years of personal experience, Ulrich (1984, unpublished paper) observed that many behavioral researchers hardly ever see the animals themselves. Instead, they become preoccupied with the data produced by the animals via pressing levers, pecking keys, running mazes, etc. Investigators write about animals in journals and read about animals but hardly ever interact with them. 
Many researchers are not so much interested in animals as with the computerized, sterilized equipment which brings in reports on the animal's behavior. Pratt (1980) forcefully makes the point, "What they seem to be interested in are the distortions, the pathology of behavior: either the fragments which remain after surgical or other mutilations have destroyed the marvelous wholeness of a functioning organism, or the reflex jerks teased out by any of the myriad of prods, punishments, or pleasures which the ingenuity of a researcher can devise."

Any analysis of the psychological motivations of animal researchers would be incomplete without reference to the pressure to publish. Peters and Ceci (1982) noted that the "publication count" can have important consequences for entire departments in terms of reputation, the quality of graduate students and faculty, and the awarding of competitive grants. In a excellent recent analysis of the general issue (not specifically addressed to the animal research controversy), Mahoney (1985) declared:

Publication, for example, lies at the very heart of modern academic science-at levels ranging from the epistemic certification of scientific thought to the more personal labyrinths of job security, quality of life, and self-esteem.... Our academic science departments are active participants in the maintenance and inflation of "publish or perish" policies (cf. Conference Board of Associated Research Councils 1982). Teaching excellence, creative thinking, and all manner of other valuable attributes will do little to earn security in academic science if they are not accompanied by published payment to the piper of tenure (p. 30)... This observation highlights the important role played by publication in the recognition, selection, and nurturance of an idea or research theme. Those scientists who successfully publish their work are not only insuring the survival of their ideas, but they are also enhancing their own chances for obtaining employment, making vertical professional moves, and receiving grants, promotions, and tenure. They are, in other words, protecting and projecting their personal careers primarily through the vehicle of publication (p. 31).

Protecting and projecting their personal careers through publication of animal research can sometimes translate into a militant selfrighteousness and resistance to dialogue, qualities at complete odds with the academic tradition of free inquiry and debate. One such personal experience occurred as a graduate student at the University of California, Los Angeles. In response to my call for an extended colloquium on animal research, one departmental researcher responded in the following fashion:

Thank you, but I choose not to participate because I think the discussion would be a waste of time. You wish to abolish animal experimentation for personal motives, and for these very reasons, I wish to pursue animal research in the traditional scientific and medical model. The issue is polarized, the rhetoric is flatulent, and the debate would be self-serving and futile. 
Pain, injury, disease, privation and stress are imposed upon animals by pet owners, sportsmen, farmers, butchers, industrialists and developers, as well as animal researchers. Human population growth and hunger are destroying habitats and wiping out species after species. Abolition of experimentation upon laboratory animals would not reduce this carnage one whit.

You may lament this biological view in all sincerity, but you and your pet cat sit atop the food chain and partake of its banquet directly and indirectly. The real trick is to find a place at the table, and not on it. But, please spare us the after-dinner speeches (J. Garcia, 1981, personal communication).

Although the proposed colloquium had clearance from both the colloquium committee chairman and the acting departmental chairman, the event never took place because the animal researchers in the department simply refused to participate. Contrary to their presumed expectations, the passage of time has (fortunately) not made "the problem" go away.

Broad and Wade (1982), in a well-documented book on fraud and deceit in the halls of science, made the following comment which provides an excellent characterization of scientists as persons:

Scientists are not different from other people. In donning the white coat at the laboratory door, they do not step aside from the passions, ambitions, and failings that animate those in other walks of life. Modern science is a career. Its stepping-stones are published articles in the scientific literature. To be successful, a researcher must get as many articles published as possible, secure government grants, build up a laboratory and the resources to hire graduate students, increase the production of published papers, strive to be awarded a tenured post at a university, write articles that may come to the notice of committees that award scientific prizes, gain election to the National Academy of Sciences, and hope one day to win an invitation to Stockholm (p.19).

\section{The APA: Principles and Practice}

Many safeguards operate to assure that laboratory animals receive humane and ethical treatment... The American Psychological Association and other scientific professional associations have codes of ethics prescribing humane and ethical treatment of research animals, to which all members must conform. APA and other associations are currently strengthening and upgrading these requirements significantly and establishing more stringent standards of review by research committees.... The American Psychological Association has been committed to the welfare of animals and their humane use in research for more than 60 years....APA's Committee on Animal Research and Experimentation (CARE) was established in 1925. It has continuously strengthened and upgraded APA's Ethical Code and standards for animal use and care....All APA members engaging in animal research must ensure "appropriate consideration for the comfort, health and humane treatment" of laboratory animals (APA pamphlet 1984). 
It must be noted that the APA Committee on Animal Research and Experimentation (CARE) notwithstanding, never once in APA's history has an APA member been sanctioned in any form for alleged unethical treatment of animals. Representatives of the 250 APA-member Psychologists for the Ethical Treatement of Animals (PsyETA) have noted that historically the CARE committee has been heavily invested in protecting the animal scientist rather than the animals. ${ }^{*}$ CARE has actively been promoting the use of animals (e.g., via publication of "exemplars" of positive research). Complaints to CARE have been rare (due to the cumbersome and risky reporting process) and rarer still have they been actively investigated.

Since 1981, the APA Committee on Scientific and Professional Ethics and Conduct (CSPEC) has had the responsibility for inquiry into charges of animal abuse, although CSPEC has no specific expertise in this area. CSPEC'S most significant action to date has been to absolve an APA member (Edward Taub) of ethical wrongdoing - in spite of the fact that the National Institutes of Health considered the Taub case serious enough to permanently revoke his grant based on substandard veterinary care provided to deafferented monkeys. Taub was initially convicted for cruelty to animals under Maryland State law (later overturned on a technicality, not on merit, by the Maryland Court of Appeals) and to date the APA has awarded Taub $\$ 16,000$ for his legal expenses. No cases of "failure to ensure welfare of animal research subjects" have been investigated by CSPEC for 1983, 1984, or 1985 to date.

APA's current Ethical Principles for the Care and Use of Animals was adopted in 1979 and incorporated in 1981 into APA's Ethical Principles for Psychologists as Principle Ten. It reads in part, "The investigator ensures the welfare of animals and treats them humanely. Laws and regulations notwithstanding, the animals' immediate protection depends upon the scientist's own conscience." To sample the quality of both the APA's safeguards and the "conscience" of investigators, a complete survey was done of APA-published animal research for the first half of 1984 (complete results available from this author). This survey was deliberately limited to very recently published research since this presumably represents APA's current attitudes, policy and interpretation of "humane." Among the procedures to which animals were subjected were:

a) up to sixty seconds of inescapable shock (Minor and LaLordo 1984);

b) up to 360 shocks in 1.1. hour (Anisman et al. 1984);

c) up to 47.5 hours of of water deprivation (Poulos and Hinson 1984);

"Psychologists for the Ethical Treatment of Animals (PsyETA). Contact: Kenneth J. Shapiro, c/o Psychology Department, Bates College, Lewiston, Maine, USA 04240. 
d) food deprivation producing 75 percent of normal body weight (Kaplan 1984a);

e) repeated contact with a 126 degree $F$ hotplate (Ross and Randich 1984);

f) prolonged social isolation (Capitanio 1984);

g) elicited fighting between females in labor and males (Mayer and Rosenblatt 1984);

h) attacks upon pups resulting in death (Mayer and Rosenblatt 1984);

i) severe motion sickness (Ossenkopp and Tu 1984);

j) exposure to loud bursts of sound (Wu et al. 1984); and

k) induction of intense fear (Mineka et al. 1984).

For the uninitiated, even a cursory glance through the Journal of Comparative Psychology or the Journal of Experimental Psychology: Animal Behavior Processes (both APA journals) can be a disconcerting experience for anyone at least moderately sensitive to animals' suffering. In my view, the problem is not individual acts of cruelty but rather institutionalized cruelty of which APA is only a small part. The following excerpts, in the words of the researchers themselves, do not reveal the deliberations of "cruel" people, rather they reveal a remarkably desensitized, detached, and emotionally chilling attitude toward their animal "models." In this regard, animal researchers in psychology are far from unique.

Most published research contains multiple experiments in each journal article. For the sake of continuity, no attempt was made here to differentiate between each and every experiment within a given published report. The key consideration is that, as the APA proudly says, all research published in APA journals must also conform to the Ethical Principles:

The approaching animal would trample on the prone partner, mouth its ears and toes, run its teeth along its partner's backbone, gnaw on its skull, thrust against its back or simply sit on it, which usually resulted in grimacing, screaming, and clasping on the recipient's part (Capitanio 1984 p. 41).

"Priming" a female hamster by allowing it one biting attack on a smaller, drug-treated target hamster significantly decreased its latency to attack a subsequently presented probe target. Conversely, the latency of attacks on the probe was increased, and the number of attacks decreased, if the subject was first "satiated" by allowing it 1 hour of ad-lib access to a target followed by a series of briefer target presentations (p.66).... In the attack-satiation condition, an MT exposure target was left in the subject's home cage for 1 hour during which time the subject could attack ad lib (Potegal and tenBrink 1984 p. 68).

Each test was begun by placing one pup in contact with the female's body.... When a female was found to have bitten or killed the first pup, one additional pup was introduced (p. 179)... A further effect of 
previous maternal experience was evident in tendencies to bite or cannibalize pups.... Pup killing also appeared more often among pregnant females (p. 183).... Many or most of the females showing aggressive nest defense and immediate responsiveness to older pups may have been in labor (Mayer and Rosenblatt 1984, p. 187).

Experimental evidence for motion sickness in non-human primates... and cats and dogs... is well established when vomiting is used as the criterion response (Ossenkopp and Tu 1984, p. 189).

Animals in one of these groups were maintained on a $47.5 \mathrm{hr}$. waterdeprivation regime (Saline/Deprived), but animals in the other group had free access to water in the colony room (Saline/Satiated). Four animals died during this phase (Poulos and Hinson 1984, p. 82)

Informal observations of the rats' behavior in the present experiments indicated that substantial freezing behavior was acquired following repeated exposure to shock. However, this freezing behavior was only manifested during the temporal interval immediately preceding shock presentation. Following shock presentation, there was a substantial increase in motor activity, primarily reflected by jumping and rearing responses.... On the other hand, it is still possible that shock-induced increases in arousal in some fashion reduce the rats' ability to effectively attend to the painful thermal stimuli (Ross and Randich 1984, p. 135).

Experience with an uncontrollable aversive event severely interferes with subsequent performance in several species.... For example, following exposure to unavoidable and inescapable electric shock, rats perform poorly in aversively... and appetitively motivated tasks... lose out in a food competition dominance tests... and show enhanced signs of stress, including weight loss and stomach ulcerations (p. 168)... Rats apparently exude a unique odor during experience with powerful stressors. Stressed and nonstressed rats can discriminate between the odor of stressed and nonstressed conspecifics [same species]. ... Further, rats given prior experience with shock later avoid a place in which a conspecific has been shocked (p. 169).... Reasoning that it might take greater stress to produce an interference effect in such animals, we increased the number of pretreatment shocks from 80 to 100 , and increased the difficulty of the test task by making the rat run further into each compartment of the shuttlebox to terminate shock (Minor and LaLordo, 1984, p.175).

The US was a 50-ms, 3-mA, 50-Hz AC shock delivered via stainless Autoclip wound clips positioned $10 \mathrm{~mm}$ apart and $10-15 \mathrm{~mm}$ posterior to the dorsal canthus of the right eye.... Each rabbit's right external eyelids were held open by No. 3 tailor-hooks mounted on a Velcro strap which fitted about the head. A muzzle-like headset, fitted securely about the snout, supported a transducer for detecting movements of the nictitating membrane. A small hook was attached to a silk loop sutured in the nictitating membrane of the rabbit's right eye... . During the course of the experiment, one animal in Group S150 died, and its data were discarded from subsequent analyses (Kehoe and Morrow 1984, p. 207). 
Whereas not a single failure to attempt to escape was evident in nonshocked mice, 4 mice that had been exposed to inescapable shock exhibited failures to attempt an escape response on more than 60 percent of the trials on the last test day. That performance deterioriated over sessions among mice that received inescapable shock is not particularly surprising (p. 232).... On the third day, half the mice received 360 inescapable shocks of $2 \mathrm{~s}$ duration (p. 234)... The motoric demands on the animal were increased (given that animals were required to retrace incorrect responses), hence permitting expression of the disturbances engendered by inescapable shock (Anisman et al. 1984, p. 236).

All programming of experimental events and observations was carried out in the darkened experimental room.... At the end of the $15 \mathrm{~min}$. of ledge exposure the barriers were removed, and the movable wall was pushed forward so that the ledge was now only $2.5 \mathrm{~cm}$ deep (not enough for the subjects to rest on). This wall movement also served to push the subjects onto the grid floor. During the next $75 \mathrm{~min}$. subjects were exposed to a series of fifty $0.7-\mathrm{mA}$ shocks (p. 309)... Thus an additional set of measures of fear.... has been shown to reflect the phenomenon of "fear from a sense of helplessness"... fear of the entire situation (grid floor and surrounding area) was being assessed in the fear test (Mineka et al. 1984, p. 310).

Animals in this condition spend a large amount of time facing away from the magazine wall, because animals exposed to primary frustration are known to actively engage in behavior to escape frustrating stimuli (Rosellini et al. 1984, p. 357).

In an effort to assimilate current information on psychological research (and improve its public image), last year the APA mailed an "Animal Research Survey" to several hundred graduate departments of psychology. One of the reported findings was that 252,000 animals were used in American university psychology laboratories in 1983 (APA Backgrounder 2 1984). To many familiar with the field, this total seemed surprisingly low. Upon closer examination, it became apparent that, by design or by oversight, the total was substantially underestimated for at least the following reasons: a) the survey was mailed to only 650 graduate departments whereas there are approximately 4,000 colleges and universities in the U.S.; b) the survey did not include animals used in behavioral research in other than academic settings; and c) the survey (question \# 7) did not ask for yearly totals of animals but rather was worded in such a way as to elicit information on standing totals. When the results of the survey were discussed by CARE representatives at the APA convention last year, these points were raised but the CARE Committee had no explanation. Curiously, when I later requested a hard copy of the APA survey, the form I was sent had "(per year)" typed in at the end of question 7 . The less than professional manner in which this project was handled may lead some to question the validity of the survey results and perhaps the motivations of the survey takers as well. 
The March 1985 APA Monitor reported that, "In an unprecedented step made necessary by the current political climate, Council [of representatives] adopted interim ethical guidelines for behavioral researchers who use animals in their experiments." The article also noted that, "In last minute letters to Council members, Neal Miller of Rockefeller University and Ethel Tobach of the Museum of Natural History in New York warned that the guidelines could unduly restrict scientists and did not acknowledge the importance of such research." Reviewing the new Guidelines themselves, it is hard to see why anyone would be concerned about them "restricting" anyone from anything. The only experimental procedure specifically prohibited in the eight-page document is, "Utilization of muscle relaxants or paralytics alone during surgery or other invasive procedures, without general anesthesia, is unacceptable, and should not be used for surgical restraint," a practice already forbidden in item number 4 of the current Guidelines ("Surgical procedures shall be performed under appropriate anesthesia"). The rest of the document is replete with qualifiers and loopholes such as: "when feasible," "only with justification," "used only when less stressful procedures are inappropriate," "undertaken judiciously," "only when the training objectives cannot be achieved in any other way," "alternatives should be considered," etc. The original draft of the new Guidelines did contain one highly progressive and eminently reasonable new principle, to wit, "It is recognized that certain extreme procedures may be inherently objectionable on ethical grounds." To the great dismay of many, the APA Council of Representatives dropped this enlightened provision from the draft accepted on an interim basis (personal communication, Kenneth Shapiro, Co-Coordinator, PsyETA). The Council plans to take final action on the new Guidelines in August, 1985.

\section{Ethical Considerations}

Ethical defenses of psychological research with animals (e.g., Miller 1983, unpublished paper presented at the 1983 APA convention; Coile and Miller 1984; King 1984) have relied heavily upon "straw man" tactics; i.e., set up the most extremist or even nonespoused arguments from the opposition and then knock them down. For example, King (Letters to the Editor, APA Monitor, April 1984) asserted that the animal advocate position is that, "Animals' rights are synonymous with human rights [and] animals have rights equal to humans." Clearly, the operational factor here is not equal treatment but equal consideration of relevant needs, interests, and capacities. No one is arguing that nonhuman animals have a "right" to vote, to obtain parking spaces, or otherwise be entitled to "rights" which are obviously incongruent with their own nature. What realistically has been stressed is that all animals have 
inherent interests in staying alive, being free from pain, and fulfilling their own unique evolutionary potentials. To automatically denigrate and disregard the fundamental interests of all other species in the exclusive pursuit of perceived human priorities is the quintessential essence of arrogance and selfishness.

To advocate animal rights in no way implies absolute liberty for animals any more than advocating human rights implies absolute liberty for people. Sudak (Letters to the Editor, APA Monitor, April 1984) illogically argues that, to avoid ethical inconsistency, animal rightists must allow animals to roam and breed indiscriminately. Respecting the rights of animals does not mean the abdication of human power, it means the exercise of human power in the spirit of humane stewardship. Enforcing animal birth control is entirely consistent with this spirit, particularly in light of the tragic pet overpopulation problem - a tragedy created in the first place by irresponsible human stewardship.

In a similar vein, Miller's (1983) address to the APA asserted:

One obvious implication is that we should not eat meat, eggs, or milk, wear leather shoes or furs, or sleep with down bags or pillows. Killing animals for such purposes obviously is exploitation. If animals have equal rights, we should not kill those who destroy our crops nor even fence in our fields to keep them out - changes that, if universally forced by legislation, could precipitate a major crisis of starvation in the world. We even should not starve or poison the rats that, if left to multiply freely, could cause outbreaks of typhus and bubonic plague. (p. 6).

The strategy is clear. Miller attempts to show that, carried to its "logical" extreme, respecting the rights of animals is impossible because to do so would mean giving up all means of human self-preservation and self-defense. This line of argument is obviously fallacious. For example, using it one could rule out all human research by showing that, carried to its "logical" extreme, scientific freedom would trample on the rights of the individual. No responsible animal rights advocate of which I am aware has argued that absolute respect for non-human life is mandatory, or even possible (how does one take a shower without killing millions of bacteria?). From an animal rights perspective, the issue is simply one of minimizing the level of violence and compulsive exploitation, or "getting off the backs of the animals" to the greatest extent possible.

Miller and his colleagues do make a key point, however, in noting out that an animal rights position does imply radical changes in the life-style of most individuals and of humanity as a whole, i.e., the exploitation of laboratory animals must be seen in a cultural context. Animals have been oppressed and abused in virtually all areas of human activity: for food, for furs, for "sport," for movies, etc., areas which cannot even make a pretense of "necessity." It is no coincidence that every vivisector I have met also eats animals. 
Ironically, it seems to be widely accepted among animal researchers that keeping animals in captivity and eventually killing them are of no moral significance in themselves. Bannister (1981) has observed, "We can do things to them which we never consider ethical to do to people. Animal experimentation is lauded as a solution for ethical problems." This attitude is abundantly evident in Miller's (1985) article: "Other experiments on stress, which ethically can be carried out only on animals...;" "Other experiments on animals that would be extremely difficult, impossible or unethical to conduct on people...;" "... recent behavioral research, which ethically could be done only on animals ...;" “... neuroanatomical, biochemical, hormonal, and drug studies can be carried out that, although not painful, would be unethical with people...."

Consequently, Miller (1985) is completely dispassionate and with clear conscience in referring to such traumatic procedures to animals as: "nausea-inducing agents...;" "... if animals were deprived of the sensations from a limb by cutting sensory nerves from it...;" "... used a mouse colony designed to produce stress by conflict among the mice for food, water, and space...," ".... increases the susceptibility to experimentally induced infections, to experimentally implanted cancers...;" "... the after-effects of unpredictable, uncontrollable shocks...;" “... a promising model for at least one type of human depression...;" "... analyze in more detail the anatomical damage and the permanent hearing losses... produced by exposure to various durations and types of loud sounds...;" "... behavioral tests for the suppression of pain-elicited responses...," “... test new drugs for addictive potential ...;" “... conditioned withdrawal symptoms can be elicited...;" "... complete deprivation of visual stimulation for a critical period in the infant chimpanzee's life caused the adults to show severe visual defects...;" "... separation of infant monkeys from their mothers and playmates during an early critical period in their development could produce striking and apparently permanent deficits in their social behavior, as well as certain neurotic and psychotic symptoms...;" "... infant monkeys who have been deprived of adequate mothering grow up to become mothers who neglect and abuse their children...;" "... experiments on effects of giving alcohol and other drugs to pregnant animals...;" “... experiments on various animals on the change in sex behavior that appear at puberty as a result of prenatal exposure to sex hormones...", etc. Furthermore, Miller feels no need to justify animal suffering through a cost-benefit analysis and argues against, "the fallacy of requiring that any specific experiment that causes animals to suffer must be justified by a cost-benefit expectation of directly producing a sufficient reduction in human suffering." Apparently, all's fair in love, war, and vivisection.

In a sensitive article by Sarason (1984), the author observes: 
When we speak approvingly, respectfully, and with awe about the benefits of science and technology, should we not temper our enthusiasm by the fact that those benefits in part derive, however serendipituously, from a long history of catastrophe, carnage and misery? Has the price been too high? (p. 477) ... The scientific-technological communities have been forced to recognize that no less important than what they study is how they utilize people and other animals as subjects. Initially, the response of these communities was quite negative. They viewed their critics as bleeding hearts who did not appreciate the gifts given them by science and technology or who did not understand the trade-off problem. The amount of good society derived from the customary conduct of inquiry far exceeded the harm inflicted on some people and animals. To tamper with untrammeled inquiry would be injurious to societal improvement. Today, a large part of these communities has come to see that they had been insensitive to the fact that in their roles as scientists and technologists they had to be governed by criteria deriving from society's view of what was good or bad for its citizens. In short, there were or should be restrictions on the freedom of the conduct of inquiry (p. 481).

Dumont (1976), in an article on behavioral research (not specifically focused on animal work), captured the essence of the researcher's mentality in noting that, "There is no malice in it. In fact, its most characteristic feature is the absence of ideology and moral judgment. It is a collection of perfectly decent professionals and administrators hustling their tenures... and being unconcerned with the consequences of their collective behavior."

The Oxford English Dictionary defines humane as "gentle or kind in demeanor or action; civil; courteous; friendly; obliging; marked by sympathy and with consideration for the needs and distresses of others; feeling or showing compassion or tenderness." This definition is consistent with the use of the word humane as it is generally applied to human subjects as well as with commonsense usage of the term. I believe that many types of animal research also merit the adjective humane, e.g., clinical studies, noninvasive lab work, and ethological or naturalistic observations. Vivisection, however, is another matter. In the laboratory environment, the theoretical definition of humane is to limit the suffering to the level required to complete the objectives of the research or testing. If the objectives are to induce heart disease, or to inflict cancer or diabetes, or to produce depression or even severe pain, this is still defined as "humane." I suggest to you that, at best, this constitutes a degraded and invalid use of the word "humane." At worst, it is hypocrisy and self-deception of the highest order. I also question the use of the word "humane" in view of the grossly minimal standards for animal care required by law, and the woefully inadequate enforcement of these laws (Giannelli 1985).

Animal research is also defended as being "necessary." I have noticed that "necessity" has a way of expanding to fill the volume supported by 
available funding. I think the word "necessary" is basically a cop-out and an ineffectual attempt to escape responsibility for our collective behavior. The use of animals in research is a long-standing social policy. One may support that policy or one may oppose it, but at least it should be honestly acknowledged that, to the extent we have become dependent on animals for research, we have made this choice with our eyes wide open. The word "necessary" is also inappropriate because it implies that we could not stop this practice even if we wanted to. Breathing is necessary. Sleeping is necessary. Eating and drinking are necessary. Vivisection is a choice, and to growing numbers of us, a most unfortunate and unjustifiable choice.

While ethical considerations apply across the spectrum of vivisection, the problem is particularly acute in behavioral work. Rowan (1984) asserted:

The psychologist must confront ethical questions that stem from the essential elements of his or her research, unlike the biochemist or physiologist, who may be interested in muscle function.... We thus come to the psychologist's paradox. Since we should, if consistent, confer moral worth according to some property (or properties) of the organism's nervous system, then the more suitable the animal is as a model of the human psyche, the greater should be the attention to the ethical issues relating to the research. The paradox boils down to this-the better the animal is as a model of the human psyche, the more restricted its use should be (p. 139).

Drewett and Kani (1981) raised a similar point in arguing that, "It is also here, of course, that the central moral question raises itself most acutely; for the same evolutionary insights that lead us to believe that there can be no radical discontinuity in psychological functions ought also to make us wonder whether it is proper to continue to treat them as radically different in morals." Rollin (1985) observed that, "... in studying the effect of such phenomena as fear, pain, grief, the psychologist has precluded the possibility of providing pharmacological relief... because such drugs would mask the phenomenon being studied. These unpleasant experiences form the substance of such experiments, and are not simply the unfortunate by-products of research."

Bowd (1980) has been a leading advocate of ethical reform in this area. He identified two basic arguments offered by defenders of animal vivisection: a) "It is reasonable to sacrifice the interests of animals in order to satisfy the interests of human beings;" and, b) "Animal interests may be disregarded for the advancement of knowledge or in the interests of science." Rollin (1985) contends that, "... moral questions-even this one-... are not simply matters of taste and opinion. A person's ethical beliefs are subject to rational examination and may be found incoherent, inconsistent, self-contradictory, ambiguous and so on, in just the same way as any other beliefs. The chances are...these discrepancies are more likely to be found in moral beliefs than elsewhere." Rollin notes 
several of the differences frequently cited between humans and animals (e.g., we have "immortal souls," we are at the top of the "evolutionary ladder," we are more powerful, we are rational, we use language, etc.). $\mathrm{He}$ then makes the telling point, "But merely citing differences is not enough; the differences must also have moral relevance." Using the example of human rationality (ignoring for the moment the fact that humans can also behave in a highly irrational fashion), Rollin then observes:

But what is the moral relevance of rationality? Doubtless one needs to be a rational being to be a moral agent or actor in order to be held morally responsible for what one does. But one surely does not need to be rational to be an object of moral attention and concern-consider children, infants, the insane, the senile, the comatose, the retarded, and so on. Furthermore, if rationality is the key feature in making something worthy of moral attention, why is so much of our moral concern devoted to aspects of human life have nothing to do with rationality (p. 923)?

Singer (1975) defined the word "speciesism" as, "A prejudice or attitude of bias toward the interests of members of one's own species and against those of members of other species." Historical analogies have been drawn between speciesism and other forms of arbitrary discrimination, such as racism and sexism. Psychologists at least acknowledge these other forms of prejudice because, in theory at least, they represent undesirable and deviant social attitudes. On the other hand, speciesism is as invisible to most of us as is water to a fish. We live in a sea of speciesism. It is the norm, the unchallenged standard which seemingly constitutes the natural order of things. To challenge this perspective, to doubt that "people always come first" is very unusual, although not actually abnormal in a clinical sense.

Psychology has often been accused, unfortunately but I think fairly, of fostering some of the most painful and misguided animal experiments. It is not that the scientists are necessarily sadistic, but rather that the present system results in great suffering. Scientists are usually not trained for or inclined to ethical thinking, and science itself (being neutral in such matters) cannot always be relied upon to supply reasonable ethical restraints on animal research. In my judgment, the inherent callousness of most current animal research has also had unfortunate psychological and intellectual consequences for people-for the researchers themselves, for generations of students encouraged to trade empathy for inquiry, and for humanity as a whole.

Segal (1982) issued a strong appeal for ethical retrospection in this area:

Yet we seem never to question our treatment of laboratory animals and the brutalizing effect of some of our practices on ourselves and our students.... It is only a small step from ignoring the welfare of animals to ignoring the welfare of people.... If we do not model a strong 
moral sense of the sacredness of life, we can hardly expect better of our students.... Most animal welfare proponents do understand the value and the needs of science (indeed, many are scientists themselves, speaking from personal experience).... They ask for an end to wanton and unthinking cruelty.... Is this experiment necessary? Does it needlessly replicate earlier work? Could our students learn from a demonstration rather than a crudely-done experiment of their own? Could the experiment be done with an earlier-evolved species? fewer subjects? a lesser intensity of shock? with appetitive rather than aversive stimuli? with a lesser degree of starvation, social or sensory isolation, confinement, restraint, or mutilation? For how many days, weeks, months, or years should one animal be required to serve science with its pain or suffering?... Does expedience justify animal suffering? (p. 115)

Lockwood bemoaned the fact that the phrase, "ethical restraints on animal research," often leaves the uncomfortable implication that the main concern of reformers is telling people what they cannot do. Lockwood concluded, "But having an ethical point of view can open many doors, adding validity to studies of animal consciousness, cognition, intelligence, and the diversity of relationships that exist between human and animal. Having an ethical point of view restrains nothing that is truly in the spirit of sound and creative scientific inquiry."

\section{Alternatives to the Status Quo}

In recent years, a large number of articles have appeared which have both critiqued contemporary psychology's overreliance on laboratoryencapsulated research and offered suggestions for both more humane and more externally valid ways of doing things. In an article on the roles of naturalistic observation in comparative psychology, D.B. Miller (1977) took note of a problem that has gotten worse with time, "The literature is becoming increasingly inundated with examples of the importance of species variables in designing, conducting, and interpreting laboratory experiments.... Comparative psychology has a great deal to gain by orienting its research around the animal in its world." Tunnel (1977) discussed an expanded definition of field research:

When the psychological researcher operationalizes the dependent measures, the treatment, and the background setting in real-world terms, his investigation may yield findings that might never have been obtained otherwise. The total effect of operationalizing all variables in real-world terms is greater than the effect of employing any of the three naturalistic dimensions singly. Not only are unexpected findings often obtained, but the findings are generally stronger, more convincing, and more highly valued by the research community. In short, the research is more meaningful.(p. 430).... Although the problem of external validity is not fully soluble, naturalistic studies do possess more potential for achieving greater generalizability than do laboratory studies, simply because the former are conducted in real-world contexts, 
to which all research ultimately seeks application (p. 434)... Learning to recognize naturalistic dimensions and learning to exploit them will require some reeducation among psychologists to the end that the response of entering the lab when one is stimulated by a research question becomes less automatic. The real world can become the primary laboratory, with recourse to experimental laboratories as the problem dictates. Ultimately, psychology seeks basic understanding of natural behaviors, natural treatments, and natural settings. They should be actively exploited in our research from the very beginning (p. 436).

In one of the most astute and compelling articles of its kind, Petrinovich (1979) discussed the concept of "probabilistic functionalism." Owing to its direct contribution to the issue at hand, the article is deserving of quotation at length:

Our application of this [scientific] method has led us to overrely on the laboratory-encapsulated, simple linear process model that prevailed in the older physical sciences. The strict reliance on these procedures seems not to be expanding our range of understanding, and this has caused serious consternation among some who study those aspects of psychology that must, by definition concern themselves with behavior in a context... This turn of events is even more distressing when one realizes that an adequate paradigm was developed by Darwin in $1859 \ldots$. There has been concern expressed recently regarding the ability of the science of psychology to deal with significant behavioral issues at an adequate level of complexity. This concern has taken the form of questioning the adequacy of traditional experimental research procedures for yielding generalizations beyond the particular experimental paradigm... I am convinced that the time has come for us not only to question the degree of reliance that has been placed on the systematic research paradigm but to call for its overthrow to the extent that anyone attempting to generalize to representative situations on the basis of data gathered within a systematic framework should be compelled to justify the generalization. In short, this is a call for a scientific revolution in the Kuhnian sense (Kuhn 1970). (p. 373).

The point is that unless variables are represented proportionally to their frequency of occurrence in the situations to which we want to generalize, we cannot establish the probable importance of variables in controlling the behavior of organisms ( $p$. 374-75).... The generality of psychological principles is diminished seriously by failing to sample situations. Because of this failure we have little information concerning the situational determinants of behavior and know little about the manner in which organisms use the resources of the situation to support behavior patterns (p. 376).... If we are to understand the behavior of organisms it will be necessary to extend the basic definition of psychology to read similarly to that suggested by Brunswik: The science of organism-environment relationships (p. 378).

The narrow laboratory-derived "laws" of the learning theorists have been found to be inadequate to apply to the instances of broader situational generality... The essential artificiality of the laboratory and the usual lack of any essential relationship of the laboratory setting to an organism's adaptive capacities do violence to the integrity 
of behavioral units. Since both the brain and behavior evolved as organized functional entities, we must understand the integrity of these entities before we can understand the mechanisms regulating them (p. 383)... If the situations are not representative, if our subjects are not representative, and if our behavioral samples are not representative, then no analytic method is of much value-no matter how sophisticated we might be in its use... Theories of behavior must be developed within the context of the environment, since it is the environment that provides both the stimulus and the response supports for behavior. Only when the capacities of the organism are considered as a part of the ecological setting can behavioral laws of adequate generality be developed (p. 388).

Although I am opposed to the exploitation of animals in the name of science, it should be abundantly clear that we can learn a lot from animals (and should) without removing them from their natural environments or acting against their interests. There are situations, however, when ethological or field research is inadequate for the subject of inquiry and laboratory research may be in order. This is not, of course, to say that we are entitled to do something aversive to animals simply because there is no other way to get the information. One cannot justify pursuing an experience using the circular logic that, without pursuing the experience, one could not have it. Nor are good intentions enough. Noble intent ought to be considered necessary but not sufficient ground for pursuing any type of research-especially on subjects incapable of giving informed consent. At times this may be less than convenient or expedient, but its justification rests not with its convenience or expediencey, but rather by virtue of the unnecessary suffering it avoids.

Granted that there are justifiable laboratory procedures which: a) are noninvasive; and/or $b$ ) done for the direct benefit of the specific animals involved, what general recommendations might one offer to make the laboratory environment more humane as well as productive? Lockwood (1984) presented some excellent suggestions, here summarized:

\section{1) Study the history and philosophy of the scientific method.}

Good science begins with a good question, followed by keen observations; avoid becoming a "behavioral data collector" of inert and stagnating information simply because it can be readily analyzed and quantified.

\section{2) Fit the technology to the question, not vice versa.}

Don't allow the technology to dictate the methodology; profound questions may be explored in elegantly simple ways; consuming large amounts of electricity, paper and animals' lives is not very imaginative.

\section{3) Get your hands dirty.}

Study your animals up close and personal, not simply the data they generate; appreciate the difference between discovering behavior of interest vs. inducing behavioral oddities; focus on studies with animals rather than experiments on animals. 
4) Don't be afraid of empathy and anthropomorphism as sources of hypotheses.

Simplistic or mechanistic interpretations are a long way from understanding; precise predictions of sterile behavior are irrelevant; empathy allows one to make more meaningful predictions which can be empirically tested.

\section{5) Provide your subjects with suitable environments.}

The animal facilities should be designed around the needs of the animals, not the convenience of the caretakers; enriched environments stimulate a wealth of diverse behavior you'd otherwise never discover.

6) Don't be afraid of anecdotes as a source of hypotheses. Anecdotes tell us about the range of animal abilities and experiences.

\section{7) Appreciate the individuality of animals.}

Creative questions come from being alert to the subtleties of behavior; individuality is biological reality.

\section{8) Examine your motives and self-image.}

Stop playing the role of "noble scientist;" find the source of your defensiveness toward criticism.

\section{9) Keep your sense of humor.}

If you've lost touch with the inconsistencies and absurdities so common in the behavior of humans and other animals, you're missing a lot of fun as well as inventive observation.

\section{0) Keep your sense of awe.}

The greatest deterrent to creative thought is the belief that you know it all.

We have considered the alternative of studying animals in real world environments, touched on the ethical advantages of clinical research done to benefit the animals themselves, and reviewed suggestions for bringing creative kindness into the laboratory. All of this is good, but we must eventually face up to the fact that, to learn about the psychology of people, one needs to study people. This is surely no revelation. Even animal research advocates who defend the practice to the hilt concede that over ninety percent of current behavioral studies are based on people. (APA Backgrounder 2. 1984). It should come as no surprise to learn that, in general, the best alternative to the use of animals in psychological research is ourselves. This is fair and fitting given that we are supposed to be the beneficiaries of such research. By its very nature, such research is inclined to be both more relevant and more ethical. The proliferation of human subject protection committees and greater attention to issues of informed consent are exceedingly healthy developments. What is needed is an analogous (don't read "identical") set of ethical standards for animal research, not the current lipservice and paper shuffling that pose and posture as "Ethical Guidelines." 
As psychologists, we must also be particularly concerned with psychological alternatives; recognition that vivisection is a choice, not an imperative; ceasing to regard animals as laboratory "tools" or simply means to self-serving human ends; rather, appreciating that animals are fellow sentient beings with interests and needs of their own which should be respected; and a genuine reexamination of our attitudes about ourselves, including the tough admission that historically Homo sapiens have always greatly overrated our sense of being "the chosen," a sort of species version of "manifest destiny."

In terms of improvements in human health, both medical and psychological, there is increasing recognition that primary prevention is our greatest alternative. Hamburg (1982; former president of the National Academy of Sciences' Institute for Medicine; in Cohen 1985) observed:

We have missed valuable opportunities to reduce our burden of illness by underinvesting in programs for disease prevention and health promotion. Over the last decade, it has become increasingly clear that cardiovascular disease, cancer, stroke and accidents - which together account for nearly 75 percent of deaths annually - are intimately linked to a variety of health damaging behaviors ranging from smoking to drunk-driving to sendentary lifestyles. Yet policy has not matched understanding: while support for disease prevention is growing, it is miniscule compared with the support given to high technology care (p. 214).

In a very recent article for American Psychologist, Senator William S. Cohen stated, "Until now, only an insignificant fraction of our resources-less than 2 percent of the total amount spent for health care-has been devoted to keeping people well.... Many health care professionals are convinced that the next major breakthrough will come not from the research laboratory, but through changes in our individual lifestyles" (Cohen 1985).

\section{Concluding Remarks}

Psychology is an honorable profession, and the vast majority of my colleagues I believe to be honorable persons. The "sins" of the behavioral animal researcher are particularly disturbing to me, not because they are so different in quality from other types of animal abuse (they aren't), surely not because they constitute in quantity the greatest amount of cruelty (they are only a tiny part of the problem), but mainly because I am grieved to see my beloved profession glorify and engage in behavior so unbecoming of civilized humanity.

I believe the most valuable things we have learned through animal research are insights into the human mentality. These insights have arisen from direct analysis of researchers at work, not from tenuous 
extrapolations to ourselves based on animal behavior in highly artificial laboratory environments. We have learned that otherwise compassionate people can become remarkably desensitized and detached from the suffering they inflict upon animals. We have learned that highly intelligent people can be engaged in the most trivial or eccentric research yet convince themselves that their work is important. We have learned that, as a species, we can be remarkably uncivilized, aggressive and selfish.

If there is one key word which, for me, sums up human "speciesism," that word is arrogance. Our attitude and behavior toward other animals is rooted in unjustified human arrogance; that is, in unchallenged assumptions regarding human superiority, uniqueness, and self-importance. This rather sweeping hypothesis is supported by any honest backward glance at our historical self-portraits. The major scientific revolutions have progressively dethroned Homo sapiens from a fictional place of unique creation. The Copernican revolution showed us that we are not situated at the center of the universe. The Darwinian revolution showed us that we are biologically related to other earth animals. The Freudian revolution demonstrated that our behavior is powerfully influenced by unconscious and irrational aspects of the psyche; and the Einsteinian revolution even pulled out from under us our assumptions about absolute space and time. Despite the staggering importance of these scientific revolutions, for the most part, we still behave as if we were the "Special Darlings" of the universe, ecologically and ethically central to creation.

A major irony of speciesism is that all the available evidence to be found in the temple of science contradicts the "Special Darling" theory. The hardest of hard physical sciences, physics, teaches us that at the atomic and subatomic levels, the matter which constitutes the human body is made of the same basic particles and subject to the same primal forces, as are all other types of matter. On the cosmic scale, the evidence is even more impressive. We now realize that the earth itself occupies an inconspicuous position in the Milky Way galaxy which consists of over 100 billion stars. Our galaxy itself is only one of more than one billion observable galaxies. One of our "closest" neighbors is M 31, the Andromeda galaxy. M 31 is only 2.2 million light years away; that is, thirteen million trillion miles, or $13 \times 10^{18}$ miles. Our Milky Way, M 31 , and sixteen other galaxies are roughly clustered together in what is affectionately called "the local group." As its name implies, the "local group" is only one of the many clusters of galaxies,some estimated to be two to three billion light years away. The most distant energy sources yet discovered are quasars, estimated to be five to fifteen billion light years away. Obviously, these dimensions are completely unimaginable to our little minds. Perhaps that partly explains why the message of our triviality doesn't get absorbed, doesn't make the headlines. I am always 
impressed by those cosmological calendars we have all seen-where January 1st is scaled to represent the beginning of the known universe and December 31st represents today. On such a scale, the earth was born in September and humanity-come-lately came on the scene a few seconds before midnight on December 31st.

The point I am trying to capture is that if ignorance ever served to justify our arrogance, our speciesism, that excuse is no longer valid. The arrogance of vivisectors, to me, represents a particularly vile anachronism, a throwback to the days when we didn't know better. Having only lately clawed our way to the top of the food chain, humanity is still drunk with power. On earth, at least, we have become the unchallenged "Planetary Bullies."

I am constantly finding ironies in my analysis of speciesism. One of the most important is that we are not "pure" speciesists by any means. By that I simply mean that as a species, we are remarkably disunited and brutal toward each other. How can any species which has never known the absence of war, which allows tens of millions of its own kind to starve to death every year, how can such a species pretend to be "humane" and "civilized"? Scientific advancement, including medical and psychological technology, is, of course, a highly desirable objective. But all the animal research in the world won't save us from the number one threat to our health-ourselves. In my judgment, speciesism is a symptom of this underlying collective pathology, a pathology which is more serious now than ever before because of our lethal technological power for self-destruction. At one stage in human evolution, the full exercise of human power was essential to our continued survival. However, in the modern era of nuclear weapons and ecological erosion, the full exercise of human power is incompatible with our continued survival. The over-exercise of our strength has become manifestly selfdefeating. We should, further, remember that the Darwinian "survival of the fittest" does not mean "survival of the strongest." Ultimately, those species most fit and therefore most likely to survive are those most in harmony with their environment.

In a recent and timely article on open scientific exchange and the growth of knowledge, Mahoney (1985) issued a poignant reminder to his colleagues which I wish to pass on to mine:

Ours is a privileged profession, indeed, and that very privilege demands a corresponding sense of responsibility and commitment. As we come to more deeply appreciate that one of the cardinal features of science is its perennial openness-its freedom to grow-it is to be hoped we will examine the most salient constraints on that openness. Whatever paths and policies we pursue in our quest for knowledge, however, we can only hope to grow by remaining open to change, and that, in itself, is a most formidable challenge. (p. 37). 
As uncomfortable or incomprehensible as it may at present be to some, the changes which I and others in the animal rights movement seek are profoundly pro-human. It is not a simplistic question of whose interests, humans vs. animals, should come first. All of life's interests must be considered together as the organic unity that it is. No one needs to prove their compassion for people by condoning cruelty to animals.

As the community mental health movement was spurred by desire to address and correct those social conditions which facilitate stress and psychopathology, as a clinician I feel a professional obligation to address and correct those cultural conditions which frustrate the enormous potential of our self-actualization as a species.

In my judgment, vivisection is a grave social evil because it fosters the worst in human nature; our arrogance, aggressiveness, selfishness, callousness, and our sense of alienation from the rest of nature. It is all the more problematic because it is promoted by the intellectual elite, professional scientists pursuing their craft for the presumed welfare of humanity, leaders who are in a position to shape the society of our children and the world of their children's children. Even if one does not accept this assessment, it is clear that the essence of ethical behavior is a system of self-restraints in the pursuit of one's perceived self-interests.

We must remind ourselves that scientific progress is not invariably human progress. The continued expansion of human knowledge at the cost of human character is a pathetic trade-off which, if continued, will eventually destroy the civilization we glorify. At present, there appears to be decreasing prospects that humanity will ever make peace with itself. Many say, this being the case, how can you expect humanity ever to make peace with the rest of the animal kingdom? There is hope for animal liberation because it also represents human liberation, freeing ourselves from the ages-old dependence on animal sacrifice. There is also hope for animal liberation because other animals do not represent the threat to us which we do to each other. As a species, with good reason, we distrust and fear each other far more than we distrust and fear other animals. The only animal which threatens to push us away from the dinner table is man himself. Perhaps, just perhaps, there is hope for facilitating the peace process by first deescalating our aggression against the other, less warlike, species which inhabit this fragile earth. 


\section{References}

Ainsworth, M.D.S. 1969. Object relations, dependency and attachment: A theoretical review of the infant-mother relationship. Child Dev. 40:969-1025.

Anisman, H., Hamilton, M. and Zacharko, R.M. 1984. Cue and response-choice acquisition and reversal after exposure to uncontrollable shock: Induction of response severation. J. Exper: Psych.: Animal Behav. Processes. 10(2):229-43.

APA Backgrounder. Public Information Office. 1984. The use of animals in psychological research.

APA Backgrounder 2. Public Information Office. 1984. The use of animals in psychological research.

APA Monitor. March 1985. p. 14.

APA (pamphlet). 1984. Behavioral research with animals.

APA Summary Report for Journal Operations. 1983. Amer. Psych. 39(6):689.

Arzin, N.H. and Thienes, P.M. 1978. Rapid elimination of enuresis by intensive learning without a conditioning apparatus. Behav. Therapy. 9:342-54.

Association for Advanced Training in the Behavioral Sciences. AATBS Staff. 1984. Abnormal psychology. 3:1-87.

Bakan, D. 1972. Psychology can now kick the science habit. Psych. Today. March.

Baldessarini, R.J. 1975. Amine hypotheses in affective illness. In: Mandels, J. ed. The Psychobiology of Depression. New York: Spectrum Publishers.

Bannister, D. 1981. The fallacy of animal experimentation in psychology. In: Sperlinger, D. ed. Animals in Research: New Perspectives in Animal Experimentation. New York: John Wiley and Sons. pp. 307-17.

Baron, J. 1971. Is experimental psychology relevant? Amer. Psych. 26(8):713-6.

Basmajian, J.V. 1963. Control and training of individual motor units. Science. 141:440-1.

Beck, A.T. et al. 1979. Cognitive Therapy of Depression. New York: Guilford.

Becker, J. 1984. Behavior modification. In: 1985 review course for the national licensure in psychology by the Association for Advanced Training in the Behavioral Sciences (AATBS). 1:1-42.

Bevan, W. 1982. In: Sarason, S.B. 1984. If it can be studied or developed, should it be? Amer. Psych. 39(5):477-85.

Bowd, A. 1980. Ethical reservations about psychological research with animals. Psych. Record. 30:201-10.

Bowlby, J. 1969. Attachment and loss. Vol. 1: Attachment. New York: Basic Books.

Brewer, W.F. 1974. There is no convincing evidence for operant or classical conditioning in adult humans. In: Weimer, W.B. and Palermo, D.S. eds. Cognition and the Symbolic Processes. Hillsdale, New Jersey: Lawrence Erlbaum Assocs.

Broad, W. and Wade, N. 1982. Betrayers of the Truth. New York: Simon and Schuster.

Capitanio, J.P. 1984. Early experience and social processes in rhesus macaques (Macaca mulatta): 1. Dyadic social interaction. J. Compar. Psych. 98(1):35-44.

Chomsky, N. 1959. Review of Verbal Behavior by B.F. Skinner. Language. 35:26-58.

Chomsky, N. 1968. Language and Mind. New York: Harcourt, Brace and World.

Cohen, W.S. 1985. Health promotion in the work place: A prescription for good health. Amer. Psych. 40(2):213-6.

Coile, D.C. and Miller, N.E. 1974. Comment: How radical animal activists try to mislead humane people. Amer. Psych. 39(6):700-1.

Coleman, J.C. and Broen, W.E., Jr. 1972. Abnormal Psychology and Modern Life. 4th edition. Glenview, Illinois: Scott, Foresman and Co. pp. 149, 627.

Dalen, P. 1969. Casual explanations in psychiatry: A critique of some current concepts. Brit. J. Psychia. 115:129,132.

Demarest, J. 1983. The ideas of change, progress and continuity in the comparative psychology 
of learning. In: Rajecki, D.W. ed. Comparing Behavior: Studying Man Studying Animals. Hillsdale, New Jersey: Lawrence Erlbaum Assocs. pp. 143-79.

Drewett, R. and Kani, W. 1981. Animal experimentation in the behavioral sciences. In: Sperlinger, D. ed. Animals in Research: New Perspectives in Animal Experimentation. New York: John Wiley and Sons. pp. 175-201.

Dumont, M. 1976. Social science vs. privacy. (letter). J. Humanis. Psych. 16(3):81. Summer.

Ellis, A. 1962. Reason and Emotion in Psychotherapy. New York: Lyle Stuart.

Endler. N. and Magnussen, D. 1976. Toward an interactionist psychology of personality. Psych. Bulletin. 83(5):968-9.

Fletcher, G.J. 1984. Psychology and common sense. Amer. Psych. 39(3):203-13.

Franks, C.M. 1969. Behavior Therapy: Appraisal and Status. New York: McGraw-Hill.

Gadlin, H. and Ingle, G. 1975. Through the one-way mirror: The limits of experimental self-reflection. Amer. Psych. 30(10):1003-9.

Gangsei, D. 1983. Community psychology. In: 1985 review course for the national licensure exam in psychology by the Association for Advanced Training in the Behavioral Sciences (AATBS). 4:1-35.

Giannelli, M.A. 1985. Sacrificing animals in experiments: Vivisection excesses in modern medicine. Cogitations on Law and Govt. 2(4):75-83.

Giorgi, A. 1970. Psychology as a Human Science: A Phenomenologically Based Approach. New York: Harper and Row.

Hamburg, D. 1982. In: Cohen, W.S. 1985. Health promotion in the workplace: A prescription for good health. Amer. Psych. 40(2):213-6.

Harlow, H.F. 1974. In: Pratt, D. 1976. Painful Experiments on Animals. New York: Argus Archives. p. 89.

Harlow, H.F., Dodsworth, R.O., and Harlow, M.K. 1965. Total social isolation in monkeys. Proceed. Nat. Acad. Sci. USA. 54:90-97.

Harlow, H.F. and Suomi, S.J. 1977. Primate models of depression. In: Seligman, M.P. and Maser, J.D. eds. Psychopathology: Experimental Models. San Francisco: W.H Freeman Co.

Heffernan, J.A. and Albee, G.W. 1985. Prevention perspectives from Vermont to Washington. Amer. Psych. 40(2):202-4.

Heim, A. 1979. The use of animals in experimental psychology. Speech given to the International Association Against Painful Experiments on Animals, West Berlin.

Henry, J.P. and Stephen, P.M. 1979. An animal model of neuropsychological factors in hypertension. In: Yamori, Y., Lovenberg, W. and Freis, W. eds. Prophylactic Approach to Hypertensive Diseases. New York: Raven Press. pp. 229-307.

Hunt, H.F. 1964. Problems in the interpretation of experimental neurosis. Psych. Reports. 15:27-35.

James, W. 1890. The Principles of Psychology. New York: Henry Holt.

Kamiya, J. 1969. Operant control of the EEG alpha rhythm and some of its reported effects on consciousness. In: Tart, C. ed. Altered States of Consciousness. New York: John Wiley and Sons. pp. 489-501.

Kaplan, P.S. 1984a. Importance of relative temporal parameters in trace autoshaping: From excitation to inhibition. J. Exper. Psych.: Animal Behav. Processes. 10(2):113-26

Kaplan, R.M. 1984b. The connection between clinical health promotion and health status: A critical overview. Amer. Psych. 39(7):755-65

Kehoe, E.J. and Morrow, L.D. 1984. Temporal dynamics of the rabbit's nictitating membrane response in serial compound conditioned stimuli. J. Exper. Psych.: Animal Behav. Processes. 10(2):205-20

Keller, F. and Schoenfeld, W. 1950. Principles of Psychology. New York: Appleton-Century Crofts. p. 399.

Kelly, J.A. 1985. Psychological research and the rights of animals: Disagreement with Miller. Comment submitted to American Psychologist. 
Kimble, G.A. 1984. Psychology's two cultures. Amer. Psych. 39(8):833-9.

King, F.A. 1984. Animals in research: The case for experimentation. Psych. Today. Sept.: 56-58.

Koch, S. 1969. In: Gadlin, H. and Ingle, G. 1975. Through the one-way mirror: The limits of experimental self-reflection. Amer. Psych. 30(10):1003-9.

Kubie, L.S. 1939. The experimental induction of neurotic reactions in man. Yale $J$. of Biology and Medicine. 11:541-5.

Kuker-Reines, B. 1982. Psychology Experiments on Animals: A Critique of Animal Models of Human Psychopathology. Boston: NEAVS.

Kvale, S. 1973. The technological paradigm of psychological research. J. Phenom. Psych. 92:175-212.

Lazarus, A.A. 1971. Behavior Therapy and Beyond. New York: McGraw-Hill.

Levine, J., Schield, B. and Bouthilet, L. eds. 1971. Establishing the Efficacy of Psychotropic Agents. Public Health Service. Publication \#2138. p. 101.

Lineberry, C.G. 1981. Laboratory animals in pain research. In: Gay, W.I. ed. Methods of Animal Experimentation. New York: Academic Press. 6:237-311.

Lipsey, M.W. 1974. Research and relevance: A survey of graduate students and faculty in psychology. Amer. Psych. 29:541-53.

Lockwood, R. 1984. Kindness is creative. Paper presented at APA meeting, Toronto 1984.

Loftus, E.F., Fienberg, S.E. and Tanur, J.M. 1985. Cognitive psychology meets the national survey. Amer. Psych. 40(2):175-80.

London, P. 1972. The end of ideology in behavior modification. Amer. Psych. 27(10):913-20.

Mahoney, M. 1977. On the continuing resistance to thoughtful therapy. Behav. Ther. 8:673-7.

Mahoney, M.J. 1985. Open exchange and epistemic progress. Amer. Psych. 40(1):29-39.

Mancucella, G. 1984. Learning theory. In: 1985 review course for the national licensure exam in psychology by the Association for Advanced Training in the Behavioral Sciences (AATBS). 1:1-28.

Marks, I. 1977. Phobias and obsessions. In: Seligman, M.P. and Maser, J.D. eds. Psychopathology: Experimental Models. San Francisco: W.H. Freeman Co.

Maslow, A.H. 1954. Motivation and Personality. New York: Harper.

Mayer, A.D. and Rosenblatt, J.S. 1984. Prepartum changes in maternal responsiveness and nest defense in Rattus norvegicus. J. Comp. Psych. 98(2):177-88.

Meichenbaum, D. 1973. Cognitive factors in behavior modification: Modifying what clients say to themselves. In: Franks, C. and Wilson, G.T., eds. Annual Review of Behavior Therapy, Theory, and Practice. New York: Brunner/Mazel.

Meichenbaum, D. and Cameron, R. 1973. Training schizophrenics to talk to themselves: A means of developing attentional cues. Behav. Ther. 4:515-34.

Mellgren, R.L., Misasi, L. and Brown, S.W. 1984. Optimal foraging theory: Prey density and travel requirements in Rattus norvegicus. J. Comp. Psych. 98(2):142-53.

Miller, D.B. 1977. Roles of naturalistic observation in comparative psychology. Amer. Psych. March:211-9.

Miller, N.E. 1978. Biofeedback and visceral learning. Annual Rev. of Psych. 29:373-404.

Miller, N.E. 1980. Applications of learning and biofeedback to psychiatry and medicine. In: Kaplan, H.I., Freedman, A.M. and Sadock, B.J. eds. Comprehensive Textbook of Psychiatry 1/III. Baltimore: Williams and Wilkens. pp. 468-84.

Miller, N.E. 1983. Value and ethics of research on animals. Unpublished paper presented to the APA convention in Anaheim, California, August, 1983.

Miller, N.E. 1985. The value of behavioral research on animals. Amer. Psych. 40(4):423-40.

Mineka, S., Cook, M. and Miller, S. 1984. Fear conditioned with escapable and inescapable shock: Effects of a feedback stimulus. J. Exper. Psych.: Animal Behav. Processes. 10(3):307-23.

Minor, T.R. and LaLordo, V.M. 1984. Escape deficits following inescapable shock: The role of contextual odor. J. Exper. Psych.: Animal Behav. Processes. 10(2):168-81. 
Mowrer, O.H. and Mowrer, W.M. 1938. Enuresis: A method for its study and treatment. Amer. J. Orthopsych. 8:436-59.

Ossenkopp, K.-P. and Tu, G.S. 1984. Motion sickness in quail: Body-rotation-induced conditioned fluid aversion in C. coturnix japonica. J. Comp. Psych. 98(2):189-93.

Paul, S.M. 1977. Models of madness: Animal models of schizophrenia. In: Seligman, M.P. and Maser, J.D. eds. Psychopathology: Experimental Models. San Francisco: W.H. Freeman and Co.

Peters, D. and Ceci, S.J. 1982. Peer-review practices of psychological journals: The fate of published articles submitted again. Behav. and Brain Sci. 5:187-95.

Petrinovich, L. 1979. Probabilistic functionalism: A conception of research method. Amer. Psych. 34(5):373-90.

Pion, G.M. and Lipsey, M.W. 1984. Psychology and society: The challenge of change. Amer. Psych. 39(7):739-54.

Potegal, M. and tenBrink, L. 1984. Behavior of attack-primed and attack-satiated female golden hamsters (Mesocricetus auratus). J. Compar. Psych. 98(1):66-75.

Poulos, C.X. and Hinson, R.E. 1984. A homeostatic model of Pavlovian conditioning: Tolerance to scopolamine-induced adipsia. J. Exper. Psych.: Animal Behav. Processes. 10(1):75-89.

Pratt, D. 1976. Painful Experiments on Animals. New York: Argus Archives. p. 164.

Pratt, D. 1980. Alternatives to Pain in Experiments on Animals. New York: Argus Archives. p. 311 .

Rajecki, D.W. 1983. Successful comparative psychology: Four case histories. In: Rajecki, D.W. ed. Comparing Behavior: Studying Man Studying Animals. Hillsdale, New Jersey: Lawrence Erlbaum Assocs. pp. 67-107.

Rollin, B.E. 1981. Animal Rights and Human Morality. New York: Prometheus Books. p. 126.

Rollin, B.E. 1985. The moral status of research animals in psychology. Amer. Psychol. 40(8):920-6.

Romanyshyn, R.D. 1971. Method and meaning in psychology. J.Phenom. Psych. 2:93-114.

Rosellini, R.A., De Cola, J.P., Plonsky, M., Warren, D.A. and Stilman, A.J. 1984. Uncontrollable shock proactively increases sensitivity to response-reinforcer independence in rats. J. Exper. Psych.: Animal Behav. Processes. 10(3):346-59.

Ross, R.T. and Randich, A. 1984. Unconditioned stress-induced analgesia following exposure to brief footshock. J. Exper. Psych.: Animal Behav. Processes. 10(2):127-37.

Rowan, A. 1984. Of Mice, Models and Men. Albany: State University of New York Press.

Ryder, R. 1975. Victims of Science. London: Davis-Poynter.

Sarason, S.B. 1984. If it can be studied or developed, should it be? Amer. Psych. 39(5):477-85.

Segal, E. 1982. Editorial. J. Anal. of Behav. 38(2):115.

Segal, E. and Lachman, R. 1972. Complex behavior or higher mental process: Is there a paradigm shift? Amer. Psych. 27(1):46-55.

Shapiro, K. 1982. A review of the NIMH grant application entitled: Production and alleviation of depression (Stephen Suomi, University of Wisconsin). In: Kuker-Reines, B. Psychology Experiments on Animals: A Critique of Animal Models of Human Psychopathology. Boston: NEAVS. pp. 5, 38.

Shotter, J. and Gauld, A. 1971. The defense of empirical psychology. Amer. Psych. 26(5):460-6.

Singer, P. 1975. Animal Liberation. New York: Avon Books. pp. 7, 47.

Skinner, B.F, 1975. The steep and thorny way to a science of behavior. Amer. Psych. $30(1): 42-49$.

Smith, M.B. 1973. Is psychology relevant to the new priorities? Amer. Psych. 28(6):463-71.

Smith, M.B. 1978. Humanism and behaviorism in psychology: Theory and practice. $J$. Humanistic Psych. 18(1):27-36.

Suinn, R. and Richardson, R. 1971. Anxiety management training: A non-specific behavior therapy program for anxiety control. Beh. Ther. 2(4):498-510. 
Tulving, E. 1979. Memory research: What kind of progress?: In: Nilsson, L.G. ed. Perspectives on Memory Research. Hillsdale, New Jersey: Lawrence Erlbaum Assocs.

Tunnell, G.B. 1977. Three dimensions of naturalness: An expanded definition of field research. Psych. Bulletin. 84(3):426-37.

Wade, N. 1982. Smart Apes, or Dumb? New York Times. (essay). 30 April.

Weimer, W.B. and Palermo, D.S. eds. 1974. Cognition and the Symbolic Processes. Hillsdale, New Jersey: Erlbaum Assocs.

Wertheimer, M. 1972. Fundamental Issues in Psychology. New York: Holt, Rinehart, and Winston. p. 194.

Wolpe, J. 1976. How laboratory-derived principles of learning have conquered the neuroses. In: Psychopathology of Human Adaptation. New York: Plenum Press. pp. 291-306.

Wu, M.-F, Krueger, J., Ison, J.R. and Gerrard, R.L. 1984. Startle reflex inhibition in the rat: Its persistence after extended repetition of the inhibitory stimulus. J. Exper Psych.: Animal Behav. Processes. 10(2):221-8. 